\title{
A methodology for in-situ and remote sensing of microphysical and radiative properties of contrails as they evolve into cirrus
}

\author{
H. M. Jones ${ }^{1}$, J. Haywood ${ }^{2,3}$, F. Marenco ${ }^{2}$, D. O’Sullivan ${ }^{2}$, J. Meyer ${ }^{4}$, R. Thorpe ${ }^{2}$, M. W. Gallagher ${ }^{1}$, M. Krämer ${ }^{4}$, \\ K. N. Bower ${ }^{1}$, G. Rädel ${ }^{5}$, A. Rap ${ }^{6}$, A. Woolley ${ }^{7}$, P. Forster ${ }^{6}$, and H. Coe ${ }^{1}$ \\ ${ }^{1}$ CAS, SEAES, University of Manchester, Manchester, UK \\ ${ }^{2}$ UK Met Office, Exeter, UK \\ ${ }^{3}$ Exeter Climate Systems, CEMPS, University of Exeter, UK \\ ${ }^{4}$ Institute for Energy and Climate Research (IEK-7), Forschungszentrum Jülich, Jülich, Germany \\ ${ }^{5}$ Department of Meteorology, University of Reading, UK \\ ${ }^{6}$ School of Earth and Environment, University of Leeds, Leeds, UK \\ ${ }^{7}$ Facility for Airborne Atmospheric Measurement, Cranfield University, Bedford, UK
}

Correspondence to: H. M. Jones (hazel.jones@manchester.ac.uk)

Received: 2 March 2012 - Published in Atmos. Chem. Phys. Discuss.: 20 March 2012

Revised: 23 August 2012 - Accepted: 25 August 2012 - Published: 11 September 2012

\begin{abstract}
Contrails and especially their evolution into cirruslike clouds are thought to have very important effects on local and global radiation budgets, though are generally not well represented in global climate models. Lack of contrail parameterisations is due to the limited availability of in situ contrail measurements which are difficult to obtain. Here we present a methodology for successful sampling and interpretation of contrail microphysical and radiative data using both in situ and remote sensing instrumentation on board the FAAM BAe146 UK research aircraft as part of the COntrails Spreading Into Cirrus (COSIC) study.

Forecast models were utilised to determine flight regions suitable for contrail formation and sampling; regions that were both free of cloud but showed a high probability of occurrence of air mass being supersaturated with respect to ice. The FAAM research aircraft, fitted with cloud microphysics probes and remote sensing instruments, formed a distinctive spiral-shaped contrail in the predicted area by flying in an orbit over the same ground position as the wind advected the contrails to the east. Parts of these contrails were sampled during the completion of four orbits, with sampled contrail regions being between 7 and 30 min old. Lidar measurements were useful for in-flight determination of the location and spatial extent of the contrails, and also to report extinction values that agreed well with those calculated from the microphysical data. A shortwave spectrometer was also able
\end{abstract}

to detect the contrails, though the signal was weak due to the dispersion and evaporation of the contrails. Post-flight the UK Met Office NAME III dispersion model was successfully used as a tool for modelling the dispersion of the persistent contrail; determining its location and age, and determining when there was interference from other measured aircraft contrails or when cirrus encroached on the area later in the flight.

The persistent contrails were found to consist of small $(\sim 10 \mu \mathrm{m})$ plate-like crystals where growth of ice crystals to larger sizes $(\sim 100 \mu \mathrm{m})$ was typically detected when higher water vapour levels were present. Using the cloud microphysics data, extinction co-efficient values were calculated and found to be $0.01-1 \mathrm{~km}^{-1}$. The contrails formed during the flight (referred to as B587) were found to have a visible lifetime of $\sim 40 \mathrm{~min}$, and limited water vapour supply was thought to have suppressed ice crystal growth.

\section{Introduction}

Contrails, and their spreading into cirrus, are one of the most visible human influences on the Earth's climate (e.g. Zerefos et al., 2003; Stordal et al., 2005). Contrails reflect solar radiation and trap outgoing terrestrial long-wave radiation, with the latter effect expected to dominate for contrails and 
thin cirrus: resulting in a positive radiative forcing (Forster et al., 2007; Haywood et al., 2009). Contrails therefore have the potential to contribute a significant warming of climate over the coming century (Fuglestvedt et al., 2008). Net radiative forcing due to aircraft induced cloudiness is one of the largest single aviation-related radiative forcing components, outweighing the radiative forcing due to aircraft carbon dioxide emissions, although the uncertainty in the former is relatively large (e.g. Boucher, 2011; Burkhardt and Kärcher, 2011). For 2005, estimated net radiative forcing of aircraft-induced cloudiness, using observed trends in cirrus cloudiness, was +10 to $+80 \mathrm{~mW} \mathrm{~m}^{-2}$ (Stordal et al., 2005; Forster et al., 2007; Lee et al., 2009), with the global radiative forcing due to line-shaped persistent contrails being $\sim 10 \mathrm{~mW} \mathrm{~m}^{-2}$ (Forster et al., 2007).

If atmospheric conditions are favourable for contrail formation, a contrail will persist if the environment is supersaturated with respect to ice. The ice crystals can grow by condensation of entrained water vapour (Schröder et al., 2000), but will evaporate if the environment becomes sub-saturated with respect to ice. The number concentration and size of contrail ice particles at formation are determined by the water activation and ice nucleation properties of plume particles and the very high plume cooling rates involved (Kärcher et al., 1996). Heymsfield et al. (2010) note that most contrail measurements to date have been made using light scattering probes (e.g. FSSP - Forward Scattering Spectrometer Probe, MASP - Multi-Angle Scattering Probe) and 2D imaging probes (e.g. 2-D-C), with sparse observations of contrail ice particle shape. Past contrail experiments have mainly focussed on sampling very young contrails close behind the source aircraft, e.g. Kärcher (1999) describes particle number size distributions $\left(>2000 \mathrm{~cm}^{-3}\right.$ of ice particles between 0.5 and $5 \mu \mathrm{m}$ ) in fresh contrails (plume age of $1 \mathrm{~s}$ ) at a distance of $250 \mathrm{~m}$ from the generating aircraft. Other studies have also shown initial ice crystal concentrations to be $>1000 \mathrm{~cm}^{-3}$ in fresh contrails, (e.g. Heymsfield et al., 1998 - using MASP, 2-D-C, sampling behind contrailing aircraft) decreasing by dilution to concentrations of less than $100 \mathrm{~cm}^{-3}$ within the first few minutes (e.g. Poellot et al., 1999 - using 2-D-C and FSSP, sampling behind contrailing aircraft; Febvre et al., 2009 - using 2-D-C, FSSP and polar nephelometer, sampling various commercial aircraft contrails). Mean effective radii of young contrail ice crystals derived from in situ data show crystals are $<2 \mu \mathrm{m}$ initially (e.g. Heymsfield et al., 1998; Baumgardner and Gandrud, 1998 using MASP, sampling behind contrailing aircraft; Petzold et al., 1997 - using PCASP (Passive Cavity Aerosol Spectrometer Probe), FSSP, MASP, and MASS (Mobile Aerosol Sampling System), sampling behind contrailing aircraft), increasing due to condensation to values of up to $5 \mu \mathrm{m}$ in contrails with ages of $30 \mathrm{~min}$, and $10 \mu \mathrm{m}$ after $\sim 1 \mathrm{~h}$ (e.g. Schröder et al., 2000). Schröder et al. (2000; using FSSP and impaction technique, sampling behind contrailing aircraft) found generated ice crystals were $\sim 8 \mu \mathrm{m}$ with concentrations rapidly reducing to $10-15 \mathrm{~cm}^{-3}$ due to plume mixing. Ice crystals habits were regularly shaped crystals and therefore distinct from young cirrus. Heymsfield et al. (1998) and Lawson et al. (1998) report microphysical data from a contrail formed in high ice supersaturation (up to $60 \%$ at $-52^{\circ} \mathrm{C}$ ) conditions. Under these conditions they noted a difference between the dominant crystal habit in the core of the contrail, where they report concentrations of $10-100 \mathrm{~cm}^{-3}$ consisting of $1-20 \mu \mathrm{m}$ plate/columnar crystals, and at the periphery of the contrail they report columnar/rosette crystals $>100 \mu \mathrm{m}$ at concentrations $\sim 10 \mathrm{~cm}^{-3}$, similar to Poellot et al. (1999). They suggest that turbulence allows some crystals to be selected for preferential growth, where these resulting periphery ice crystals have similar habits to those of the ambient cirrus found in the area. This mechanism allows contrails to form precipitation streaks. From the same study (SUCCESS - SUb-sonic aircraft: Contrail and Cloud Effects Special Study), Goodman et al. (1998 - using an impaction technique, sampling behind contrailing aircraft) report data from a different contrail $\left(-62{ }^{\circ} \mathrm{C}, \mathrm{RH}\right.$ not reported) where after $1 \mathrm{~min}$ of growth $5-10 \mathrm{~cm}^{-3}$ of $\sim 5 \mu \mathrm{m}$ particles were present and were found to consist of $75 \%$ hexagonal plates, $20 \%$ columns, $5 \%$ triagonal crystals. Baumgardner and Gandrud (1998) report data from the same flight, and they suggest that the high concentration of small $(2 \mu \mathrm{m})$ ice crystals $\left(\sim 200 \mathrm{~cm}^{-3}\right)$ inhibit diffusional growth by depleting the available water vapour.

As contrails age, turbulence due to shear may lead to the loss of the line-shaped appearance and growing ice crystals may descend to lower levels in fall streaks (e.g. Knollenberg, 1972). Whilst still young, contrail widths can be derived from in situ measurements (e.g. Poellot et al., 1999: < 15 min old contrails at $100-300 \mathrm{~m}$ width). Haywood et al. (2009) observed line-shaped contrails spreading into cirrus using satellite data, where cirrus (covering up to $50000 \mathrm{~km}^{2}$ ) was still present $12 \mathrm{~h}$ after the contrail was produced. Confirmation from independent satellite measurements showed that the positive longwave radiation forcing outweighed the negative solar radiative forcing, however, there were no in situ data for this case study.

Aircraft measurements of contrail ice particle size distributions only exist for line-shaped contrails as once they lose their initial shape they are very difficult to identify in situ without additional remote sensing support, e.g. lidar and satellite observations. The transition of persistent line-shaped contrails into cirrus-like clouds is neither well understood nor well represented in climate models, despite the fact this is likely to be one of aviation's largest effects (Forster et al., 2007). It must also be noted that contrails may evolve at different rates in warmer or colder environments. The wide range of supersaturation conditions under which contrails persist have not yet been fully explored. Furthermore, older measurements of in-situ contrail ice crystals where crystals greater than a few hundred micrometres in diameter were present are likely to be susceptible to artefacts as they were taken by probes susceptible to shattering of larger particles 
on the inlet (e.g. Korolev et al., 2011; McFarquhar et al., 2007), producing artificially enhanced number concentrations. Newer probes that have been designed to reduce shattering and allow corrections for any remaining artefacts have the potential to lead to improved parameterisations for contrails.

Aviation-induced cirrus is known to be very important for climate change and yet it is poorly observed, little understood and currently not well modelled (e.g. Forster et al., 2007); though recent work shows progress (e.g. Burkhardt and Kärcher, 2011; Rap et al., 2010a). Radiative forcing estimates are affected by uncertainties related to model representation of upper tropospheric humidity and cloud. The representation of clouds is a major source of uncertainty in climate simulations and the same problems (small-scale processes not resolved at climate model grid spacing) also affect the representations (parameterisations) of contrail cirrus. The ultimate aim of the current study: COntrails Spreading Into Cirrus (COSIC), is to build a physically based parameterisation of contrail spreading into cirrus; to determine its role in climate change and to test its importance compared to the initial line-shaped contrails. In order to achieve this, observations of contrail microphysical properties were collected using the UK's FAAM (Facility for Airborne Atmospheric Measurements) BAe-146-301 Atmospheric Research Aircraft under a range of conditions.

In situ measurements of aircraft contrails are particularly difficult to perform, yet there is a clear need for more observational data (e.g. Heymsfield et al., 2010; Burkhardt et al., 2010). Here, we present a case study for a methodology that we believe can increase our understanding of contrail ice microphysics by allowing indiscriminate sampling as a function of age. Utilising forecast models allows the determination of flight regions most suitable for contrail formation and sampling on a given day and application of this methodology. Meteorological conditions as well as ice number concentration and particle size distributions are reported for conditions outside those previously reported, using current state of the art instrumentation with reduced inlet shattering effects. The data are interpreted alongside data from remote sensing instrumentation (e.g. integrated in situ aircraft lidar and radiation observations) which together with dispersion modelling of the aircraft contrail plume, allow us to accurately report contrail age, position and spatial extent. It will be shown that this combined approach has the potential to lead to an increased scientific understanding of contrails and aircraft produced particles from their formation and throughout their evolution.

\section{Instrumentation}

The instruments providing the data used in this study were all fitted to the FAAM aircraft. They are described below, and in greater detail in Crosier et al. (2011) and the ref- erences therein. In addition several core instruments were also used, including the GPS-aided Inertial Navigation system (GIN), providing altitude (to $7 \mathrm{~m}$ uncertainty), position (to $5 \mathrm{~m}$ uncertainty) and velocity (to $0.05 \mathrm{~m} \mathrm{~s}^{-1}$ uncertainty), and temperature sensors (Rosemount/Goodrich type $102, \pm 0.3 \mathrm{~K}$ uncertainty). $\mathrm{NO}_{\mathrm{x}}$ measurements were recorded using a TE42C Chemiluminescence NO- $\mathrm{NO}_{2}-\mathrm{NO}_{\mathrm{x}}$ Analyser (Thermo Scientific, where $\mathrm{NO}_{2}=\mathrm{NO}_{\mathrm{x}}-\mathrm{NO}, 6 \%$ uncertainty). Other trace gas measurements were also recorded but are not reported here.

\subsection{Water vapour measurements}

A hygrometer (Buck Research instruments LLC, model CR2) which measures atmospheric dew-point using the chilled mirror technique was also used. In this, air is passed over a mirror-like metal surface and the temperature regulated until condensation begins to form on the mirror: this being the dew or frost point. The condensation layer is maintained at a constant level using optical detection and control, and the mirror temperature is measured using an embedded platinum resistance thermometer. Data are recorded at $1 \mathrm{~Hz}$, with uncertainties within $\pm 0.5 \mathrm{~K}$ depending on the variability of the conditions. When data from the CR-2 are not available, $\mathrm{RH}$ can be calculated using the dew point temperature reported by the General Eastern (GE) Chilled Mirror Hygrometer (Model 1011B). These data are recorded at $4 \mathrm{~Hz}$ and have a positive bias below $-25^{\circ} \mathrm{C}$ with a response time increasing to a few minutes at temperatures of $-40{ }^{\circ} \mathrm{C}$ or less. As there are known issues with both of the above instruments at low temperatures, the RH values reported in this paper are an estimate of the local conditions.

\subsection{Cloud measurements}

\subsubsection{In situ cloud microphysics}

A selection of cloud microphysics probes sampled particles over a wide size range. The PMS 2-dimensional particle size spectrometer (2-D-C, 32 diodes) uses a $\mathrm{HeNe}$ laser and a photodiode array and detection system to provide images and size-resolved particle number concentration in the size range $25-800 \mu \mathrm{m}, 25 \mu \mathrm{m}$ resolution (Knollenberg, 1970). A Droplet Measurement Technology (DMT) Cloud, Aerosol and Precipitation Spectrometer with depolarisation (CAPS-DPOL), a so-called "multi-probe" was also used. This includes a Cloud Imaging Probe (CIP-GS) and a Cloud and Aerosol Spectrometer with single particle depolarisation (CAS-DPOL). CIP-GS provides 3-level grey scale shadow images of ice particles in the size range 15-960 $\mu \mathrm{m}$ (resolution $15 \mu \mathrm{m}$ ) along with size-resolved particle number concentration. Here we do not report data from the first channel due to the uncertainty of the lower limit of this channel. CAS-DPOL is a Mie scattering spectrometer probe that detects and sizes aerosol particles and cloud hydrometeors from 
0.6-50 $\mu \mathrm{m}$ (Baumgardner et al., 2011). Here we are only using detection channels 2-26 of the available CAS channels, covering the size range $0.6-50 \mu \mathrm{m}$. We have rejected data from the first size channel due to the uncertainty of the lower limit of this channel. The CAS was calibrated using National Institute of Standards and Technology (NIST) calibration glass beads according to the manufacturers operating manual and this revealed no sizing discrepancies greater than the diameter spacing between adjacent channels (i.e. the accuracy of sizing was of the order of $\sim 15 \%$ in this size range for spherical particles with known refractive index; here we are measuring small ice crystals, so the error is larger and difficult to quantify). The CAS data were also quality checked by examining the distribution of signal amplitudes from the raw particle-by-particle data and processed using the technique outlined in Johnson et al. (2012). Investigation of the inter-arrival time data from the CAS-DPOL and CIP-GS probe showed that shattering of ice crystals on the inlet accounted for only a very small percentage of the ice crystals detected by the probe in the thin cirrus sampled here (e.g. Field et al., 2006). The CAS instrument was fitted with a single particle backscatter depolarisation detector to help distinguish aspherical ice crystals from water droplets but these data are not reported as all particles were ice. This instrument is described in detail by Baumgardner et al. (2011). For the case study discussed in this paper, the CAPS probe and subsequent data analysis was provided by Forschungszentrum Juelich (FZJ) as part of an instrument flight testing and exchange activity. It must be noted that the stated size ranges for the CIP-GS and 2-D-C are the nominal size ranges for spherical particles, and the CAS-DPOL size range is for optical, water equivalent diameters.

\subsubsection{Remote sensing}

A Leosphere backscattering lidar (ALS450) was used in a nadir-viewing geometry. Measurements were at a wavelength of $355 \mathrm{~nm}$ with an integration time of $2 \mathrm{~s}$ providing a vertical resolution of $1.5 \mathrm{~m}$. Further integration and vertical smoothing was subsequently applied to the data to improve the signal-to-noise ratio, leading to time and vertical resolutions of $6 \mathrm{~s}$ and $45 \mathrm{~m}$, respectively. At an aircraft ground speed of $\sim 100 \mathrm{~m} \mathrm{~s}^{-1}$, this integration time translates into a $\sim 600 \mathrm{~m}$ horizontal footprint. Using vertical profiles of the lidar signal, retrievals of the cloud aerosol backscatter and extinction coefficient were made using the Fernald-Klett inversion method (Fernald, 1984; Klett, 1985). This is possible because the clouds considered here are optically thin and can be treated in a similar way to aerosol layers; Marenco et al. (2011) used this method for determining the optical depth of volcanic ash from the Eyjafjallajökull eruption. For the lidar retrievals, a lidar ratio (extinction-to-backscatter ratio) of $20 \mathrm{sr}$ is assumed, and from the profiles the integrated backscatter and optical depth have been computed. Full overlap of the emitted beam with the receiver field-of-view is achieved $300 \mathrm{~m}$ below aircraft; therefore data above this altitude are not considered. It should be noted that often it is not possible to fly above the persistent contrail top (which may be above the aircraft ceiling of $\sim 10.7 \mathrm{~km}$ ); therefore in some cases the cloud integrated backscatter and optical depth estimates are limited to the bottom portion of the persistent contrail. Note also that the Fernald-Klett retrieval is strongly dependent upon the lidar ratio that is chosen. We estimate on the latter an uncertainty of $50 \%$, which translates into a similar uncertainty on the retrieved extinction and optical depth.

The Short Wave Spectrometer (SWS), measures directionally dependant radiance $\left(\mathrm{W} \mathrm{m}^{2}\right.$ steradian $\left.^{-1} \mu \mathrm{m}^{-2}\right)$ in the wavelength range $0.3-1.7 \mu \mathrm{m}$. Two Zeiss diode array spectrometer modules are connected to a custom built telescope via optical fibres. The visible module covers the range 300$1145 \mathrm{~nm}$ with a spectral resolution of $\sim 3 \mathrm{~nm}$, while the near infrared module covers the range $945-1705 \mathrm{~nm}$ and has a lower spectral resolution of $\sim 6 \mathrm{~nm}$. There are two telescopes, one for each module, with a similar but not identical field of view (FoV). For the visible module the FoV is $1.7^{\circ}$ (half angle) and for the near infrared module the FoV is around $2^{\circ}$ (half angle). The SWS telescopes can be rotated through $360^{\circ}$, however obstructions from the aircraft wing and tail mean that the regions fore $55-86^{\circ}$ and aft $61-$ $75^{\circ}$ are obscured. SWS is calibrated in the laboratory using a Labsphere CSTM-USS-2000S integrating sphere. A calibration certificate is provided by the National Physics Laboratory and this is traceable to the US NIST. We use data from the SWS instrument when in nadir viewing geometry to compliment the lidar data.

\subsection{Aerosol measurements}

Aerosol particle number size distributions from 0.1 to $3 \mu \mathrm{m}$ in diameter were provided by a Passive Cavity Aerosol Spectrometer Probe (PCASP-100, Particle Measurement Systems, with modified electronics, version SPP-200 provided by DMT; e.g. Petzold et al., 2002). Calibration and data analysis procedures for the FAAM PCASP along with software tools are described in detail by Rosenberg et al. (2012).

\section{Experimental design}

In the following sections we describe the forecast and model tools used to predict appropriate conditions and the design of the aircraft sampling methodology used to probe contrail microphysical properties and their evolution.

\subsection{Model tools}

\subsubsection{ECMWF model}

Standard operational forecasts $(+9$ to $+66 \mathrm{~h}$ forecasts, from 0 and $12 \mathrm{Z}$ analyses, given every $3 \mathrm{~h}$ ) were obtained from the European Centre for Medium-range Weather 
Forecasts (ECMWF) model and used for flight planning. The ECMWF-Integrated Forecast System (IFS) contains the cloud scheme developed by Tompkins et al. (2007), which allows for supersaturation with respect to ice. Therefore it is well suited to predict areas where persistent contrails are likely to form. The conditions needed are cold temperatures of less than about $-40{ }^{\circ} \mathrm{C}$ and supersaturation with respect to ice, $\mathrm{RH}_{\text {ice }}>100 \%$. Profiles of $\mathrm{RH}_{\text {ice }}$ were calculated from the dew point temperatures according to the formula of Sonntag (1994). The capability of this model to predict ice supersaturation over England has been shown using radiosonde data and visual contrail observations (Rädel and Shine, 2010).

\subsubsection{NAME}

The UK Meteorological Office Numerical Atmosphericdispersion Modelling Environment dispersion model (NAME III, version 6.0.1, described fully in Jones et al., 2007), is a Lagrangian particle model, which was for the case described here, initialised with $1100+$ start locations to approximate the aircraft flight path based on the in situ aircraft GPS location data. Release points were initiated at a constant aircraft altitude of $9800 \mathrm{~m}$ (the observed aircraft altitude when performing the orbital part of the flight pattern) at $10 \mathrm{~s}$ intervals. The contrail is approximated by an inert tracer which is neutrally buoyant, with a specified lifetime after which it is assumed to disappear: this lifetime is applied in order to obtain interpretable graphical representation of the flight track. The transport and dispersion of the tracer is governed by input meteorological data taken from the UK Met Office $4 \mathrm{~km}$ resolution model. To allow the contrail sampling age to be pin-pointed with ease, the dispersion in the model was deliberately reduced to allow the identification of the contrail centres. This proved very useful for interpreting the repeated in situ penetration measurements as the contrail was advected and evolved in time.

\subsubsection{Satellite data}

Polar orbiting satellite imagery (from NOAA 15) was also used to identify and track contrails formed with the FAAM BAe-146 aircraft, although due to some commercial airline activity or cloud in the area this was not always easy to identify. The case study here (B587), see Sect. 4, was however conducted off the east coast of Scotland and Northern England in otherwise clear skies and provided a particularly clear satellite identification of the contrails formed.

\subsection{Flight patterns}

The methodology outlined in this paper does not advocate a specific flight pattern. It is only essential that the chosen flight pattern allows successive uncontaminated sampling as the resultant contrails evolve. Due to limited favourable airspace regions, circular contrails, such as those produced

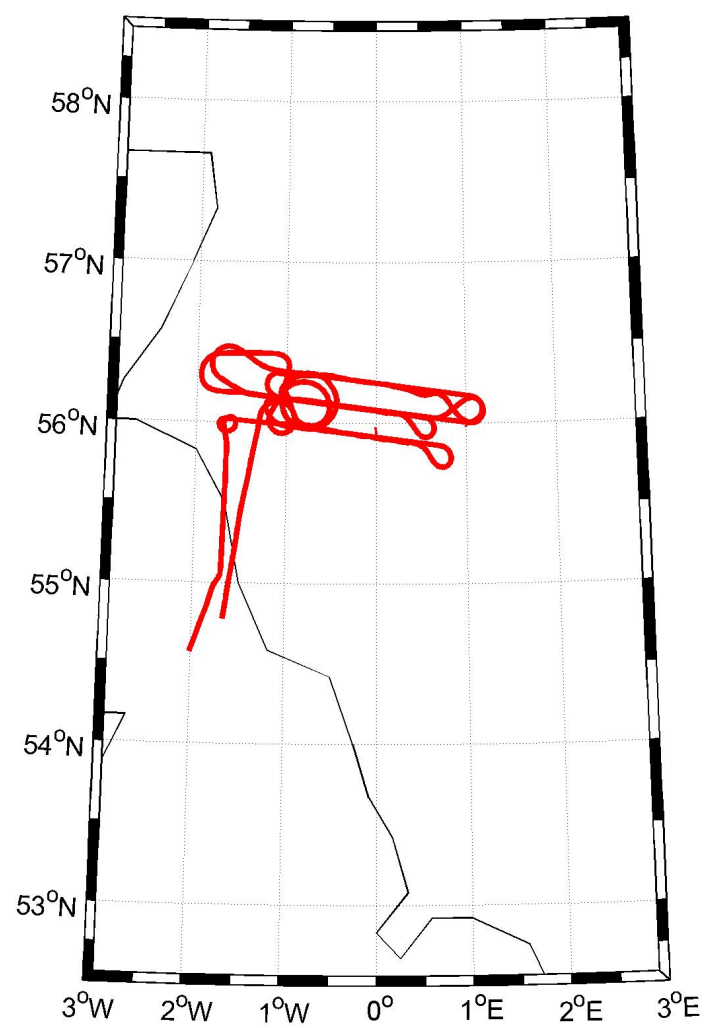

Fig. 1. The aircraft flight track for the B587 flight (19 March 2011, Take off: 14:09:29, Land: 19:22:35), see Sect. 4 for more details, taken from the on-board GPS system.

from the aircraft performing orbits, were chosen for this flight as they are a distinctive pattern (often appearing as spiral contrails due to advection, e.g. Haywood et al., 2009) that can be recognised easily in satellite images, and visually when flying at higher altitudes, see Fig. 1. This proved particularly useful when other aircraft were flying in the same area and generating confounding contrails. Repeated uncontaminated (by the sampling aircraft) sampling of orbit contrails is more difficult to carry out for orbits compared to the sampling of straight and level runs, but here we use lidar in flight to determine the position and spread of the contrails and use the NAME model post-flight to validate. Several orbits were performed over fixed ground positions; allowing brief in situ sampling of the previous orbit contrails, where advection of the contrails means sampling is not constant but brief as the aircraft intercepts earlier contrail boundaries. Physically, this method works provided the time taken for the contrail to advect a distance of twice the radius of the orbit is greater than the distance travelled by the aircraft; leading to a constraint on the ambient wind speed $\left(v_{\text {ambient }}\right)$ of $v_{\text {ambient }}<v_{\text {aircraft }} / \pi$. Straight and level runs (SLRs) at higher altitude were then used to allow the remote sensing equipment to determine radiative properties of the different aged contrails in addition to their position and spatial extent. Additional SLRs at altitudes 
lower than the orbit contrails were then conducted to allow the investigation of any fall streaks identified by the lidar system in the higher passes. Repeated sampling of the aged contrails at the formation altitude was then used to allow investigation into the spreading of the contrails into young cirrus.

\section{Case study}

\subsection{Flight B587 - 19 March 2011}

Flight B587 was performed on 19 March 2011 over the North Sea to the east of Edinburgh (14:09:29 to 19:22:35, all times are UTC). Weather conditions were noted as settled with hazy sunshine; the top of the boundary layer was recorded at $0.61 \mathrm{~km}$ with slack $\left(\sim 20 \mathrm{~m} \mathrm{~s}^{-1}\right)$ upper $(300 \mathrm{mb})$ winds. At the start of the sortie, dissipating cumulus was noted below the aircraft main flight level. There was little interference from either stratocumulus or cirrus at the start of the sortie but encroachment by both became problematic towards the end of the sortie.

The aircraft was directed towards supersaturated airspace (with respect to ice) indicated by the ECMWF model forecasts, where the aircraft commenced contrailing above $8.5 \mathrm{~km}$. Four orbits were performed at an altitude of $\sim 9.8 \mathrm{~km}$ $\left(T \sim-60^{\circ} \mathrm{C}\right)$, with the latter three over the same geographical location, followed by SLRs performed above and below the orbits to investigate the radiative impacts of the newly formed orbit contrails. This was followed by in-situ cloud microphysics measurements as the contrails aged producing a classic contrail coil (Haywood et al., 2009). This was periodically sampled whilst continuing to contrail. PCASP mean aerosol particle concentrations for out of cloud periods over $8 \mathrm{~km}$ were $28.8 \mathrm{~cm}^{-3}$ (we are unable to report reliable incloud aerosol concentrations from PCASP due to inlet contamination issues when operating in ice clouds). A series of downwind and into wind runs were then performed; the downwind leg to generate the persistent contrail and the intowind leg to sample the persistent contrail. Figure 1 shows the flight track of the aircraft in its entirety; the temperature range for the formation and sampling of contrails was -50 to $-65^{\circ} \mathrm{C}$.

The NAME III model was used (post-flight) to predict the dispersal and diffusion rates of the initial circular contrails made by the aircraft during this flight. This information subsequently proved useful in determining the portion of the contrail being penetrated as a function of age. Figure 2 shows the contrails are advected almost directly eastward, whilst dispersing, during the sampling period. The age of the contrails sampled by the aircraft can be determined to a resolution of $\pm 30 \mathrm{~s}$ by examining these sorts of images. The various contrail sampling penetrations have then been broken down into sections according to the following general categories:

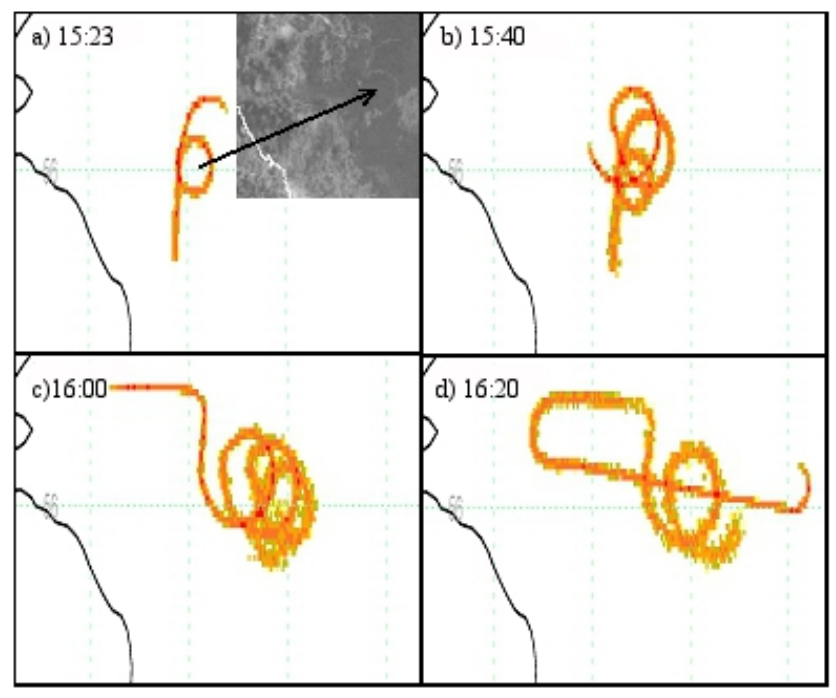

Fig. 2. The dispersion of the plume as predicted by the NAME model. (a) 15:20, (b) 15:40, (c) 16:00, (d) 16:20. The contrail is assumed to have a lifetime of $45 \mathrm{~min}$ and is removed from the analysis after this time to aid clarity. A satellite image (10.8 to $12.0 \mu \mathrm{m}$ product from NOAA 15, overpass at 15:23 UTC) is shown as part of (a), this shows contrail orbit 1, merging with contrail orbit 2 .

\subsection{1 "Fresh" contrails}

During the flight, the designated "orbit 1" was performed between 1.2 to $0.8^{\circ} \mathrm{W}$ and 55.9 to $56.2^{\circ} \mathrm{N}$, flying clockwise with a diameter $\sim 10$ nautical miles $(\sim 18.5 \mathrm{~km})$. Subsequent orbits, $2-4$, were larger with diameters of $\sim 20$ nautical miles $(\sim 37 \mathrm{~km})$. These were performed further to the east, all above the same geographical location between 1.1 to $0.4^{\circ} \mathrm{W}$ and 55.9 to $56.4^{\circ} \mathrm{N}$. All orbits were performed at $\sim 9.8 \mathrm{~km}$, with the aircraft contrailing throughout this time. During these orbits the aircraft successfully crossed prior orbit contrails at various ages. These were identified by noting several increases in particle number concentrations from the various cloud and aerosol instruments, as discussed below. Contrail ages and sources were determined from aircraft flight time and the NAME III model output. The Satellite image (10.8 to $12.0 \mu \mathrm{m}$ product, NOAA15 overpass from 15:23 UTC), Fig. 2a, shows part of orbit 1 merging with orbit 2; we can see from this image that only part of orbit 1 was persistent at the time of this image (and no contrail leading into orbit 1 is seen), but it also shows good agreement with the concurrent NAME model forecast.

\section{Contrail identification and age analysis}

Persistent contrail interceptions recorded by the CIP-GS and CAS instruments were confirmed both by increases in particle number concentrations and by comparison with the NAME model predicted contrail locations. These methods enabled identification of nine individual orbit contrail 
Table 1. Information regarding contrail penetrations made during initial orbits of Flight B587. Mean (max) CIP-GS and CAS number concentration $\left(\# / \mathrm{cm}^{3}\right)$ are reported. CAS values in square brackets are mean and max concentrations when concentrations $>50 \mathrm{~cm}^{3}$ are included. $\sim \mathrm{RH}$ is calculated from (ambient) saturated vapour pressure calculations using the de-iced temperature from the Rosemount/Goodrich sensor and dew point temperature as measured by the General Eastern chilled mirror hygrometer, at which the specific part of the contrail was formed/sampled.

\begin{tabular}{|c|c|c|c|c|c|c|c|c|c|}
\hline Pass & $\begin{array}{l}\text { Start } \\
\text { Time }\end{array}$ & $\begin{array}{l}\text { End } \\
\text { Time }\end{array}$ & Time (s) & $\begin{array}{l}\text { Contrail } \\
\text { Sampled }\end{array}$ & $\begin{array}{l}\text { Age } \\
(\mathrm{min})\end{array}$ & $\begin{array}{l}\text { CIP NC } \\
\left(\# / \mathrm{cm}^{3}\right)\end{array}$ & $\begin{array}{l}\text { CAS NC } \\
\left(\# / \mathrm{cm}^{3}\right)\end{array}$ & $\begin{array}{l}T \\
\left({ }^{\circ} \mathrm{C}\right)\end{array}$ & $\begin{array}{l}\sim \mathrm{RH} \\
\text { Range \% }\end{array}$ \\
\hline 1 & $15: 18: 25$ & 15:19:00 & 35 & $\mathrm{O} 1(\mathrm{~W})$ & 7 & $\begin{array}{l}0.007 \\
(0.014)\end{array}$ & $\begin{array}{l}0.43 \\
(6.28)\end{array}$ & -59.83 & $103 / 115$ \\
\hline 2 & $15: 26: 30$ & $15: 26: 45$ & 15 & $\mathrm{O} 1(\mathrm{E})$ & 10 & $\begin{array}{l}0.003 \\
(0.011)\end{array}$ & $\begin{array}{l}7.82 \\
(62.1)\end{array}$ & -59.79 & $105 / 113$ \\
\hline 3 & $15: 28: 30$ & $15: 29: 10$ & 40 & $\mathrm{O} 2(\mathrm{~W})$ & 9 & $\begin{array}{l}0.007 \\
(0.024)\end{array}$ & $\begin{array}{l}3.98[15.3] \\
(42.6)[446]\end{array}$ & -59.52 & $122 / 123$ \\
\hline 4 & $15: 33: 30$ & $15: 34: 00$ & 30 & $\mathrm{O} 2(\mathrm{~N})$ & 12 & $\begin{array}{l}0.001 \\
(0.002)\end{array}$ & $\begin{array}{l}1.72[85.0] \\
(41.4)[2041]\end{array}$ & -59.66 & $114 / 117$ \\
\hline 5 & $15: 35: 45$ & $15: 36: 30$ & 45 & $\mathrm{O} 1$ (NE) & 21 & $\begin{array}{l}0.013 \\
(0.034)\end{array}$ & $\begin{array}{l}0.68[42.5] \\
(10.1)[810]\end{array}$ & -59.68 & $110 / 119$ \\
\hline 6 & $15: 36: 45$ & $15: 37: 15$ & 30 & $\mathrm{O} 2(\mathrm{SW})$ & 10 & $\begin{array}{l}0.003 \\
(0.011)\end{array}$ & $\begin{array}{l}0.46[63.0] \\
(5.14)[1559]\end{array}$ & -59.72 & $112 / 116$ \\
\hline 7 & $15: 43: 45$ & $15: 44: 45$ & 60 & $\mathrm{O} 3(\mathrm{~N})$ & 14 & $\begin{array}{l}0.029 \\
(0.059)\end{array}$ & $\begin{array}{l}0.6[52.6] \\
(5.8)[2119]\end{array}$ & -59.74 & $123 / 126$ \\
\hline 8 & $15: 44: 50$ & $15: 45: 35$ & 45 & $\mathrm{O} 2(\mathrm{~N})$ & 24 & $\begin{array}{l}0.064 \\
(0.182)\end{array}$ & $\begin{array}{l}0.94 \\
(3.08)\end{array}$ & -59.67 & $125 / 122$ \\
\hline 9 & $15: 47: 00$ & $15: 49: 40$ & 160 & $\mathrm{O} 1 / 2 / 3$ & $30 / 20 / 11$ & $\begin{array}{l}0.027 \\
(0.32)\end{array}$ & $\begin{array}{l}1.0 \text { [6.25] } \\
(10.5)[572]\end{array}$ & -59.76 & $(117 / 125 / 115) / 117$ \\
\hline
\end{tabular}

"passes" and these are reported in Table 1. During these contrail passes, peak ice crystal concentrations recorded by the CIP-GS, also shown in Table 1, were found to range from 0.001 to $0.32 \mathrm{~cm}^{-3}$. The highest peak concentrations (from the CIP-GS) were observed during pass 9, when sampling the dispersed orbit contrails (see Table 1), CIP-GS values were perhaps higher for this pass as ice crystals would have had a longer growth time. High $\mathrm{RH}_{\text {ice }}$ values were seen for orbit passes 3, 7 and 8, where CIP-GS values were seen to be higher for the later passes that sampled the northern section of the contrails at age 14 and $24 \mathrm{~min}$. On several occasions when sampling contrails, sudden short-lived high increases (to $>50 \mathrm{~cm}^{-3}$ ) in CAS number concentrations were observed. For these occasions peak and mean concentration values have been reported in Table 1 where values are reported for both including, and excluding this data in lieu of potential shattering contamination not fully corrected for.

Using the NAME model predicted contrail location and aircraft location as a function of time, we see that pass 1 and pass 2 (see Table 1) sampled the orbit 1 contrail at different locations, and hence at different ages; both passes showed similar CIP-GS number concentration, though pass 2 recorded higher CAS values. Orbit 1 (O1) was re-sampled $\sim 10$ min later during pass 5, where CAS and CIP-GS number concentrations were observed to have increased: this highlights some of the difficulties in assessing contrail microphysical ice concentrations as a function of plume age.
If we focus on the passes where the CAS reported a substantial sharp increase in number concentration whilst flying through a contrail (passes 3, 4, 5, 6, 7, and 9, see italicised bracketed numbers in Table 1), peak total concentrations $>2000 \mathrm{~cm}^{-3}$ were observed, with a number increase occurring across most size channels, see Fig. 3. Increase in particle counts due to shattering has been eliminated by investigation of the inter-arrival times, so it is possible that this contribution was due to the sampling of smaller aerosol from the aircraft plume within the contrail. Unfortunately the $\mathrm{NO}_{\mathrm{x}}$ measurements were too low resolution (slow response time) to provide additional evidence here. The PCASP did not reveal any corresponding increase in concentration, however this instrument is known to have issues when sampling in ice clouds (due to shattering issues) so we cannot independently verify these high aerosol number concentrations. Much higher $\left(>2000 \mathrm{~cm}^{-3}\right)$ readings were seen with the CAS probe at various other stages of the flight (see Fig. 14a), but it is believed that these later sharp increases are from crossing the contrails of other aircraft flying in the area, since they do not appear when sampling background cirrus later in the flight.

Examining the CIP-GS size distributions in each pass we note that a shoulder occurs around $80 \mu \mathrm{m}$ for passes 3, 7, 8 and 9, with passes 7 and 8 also showing a larger number of ice particles $\sim 50 \mu \mathrm{m}$. The growth of this additional size mode cannot be simply attributed to the "ageing" of the contrail and changing external factors must be examined. 


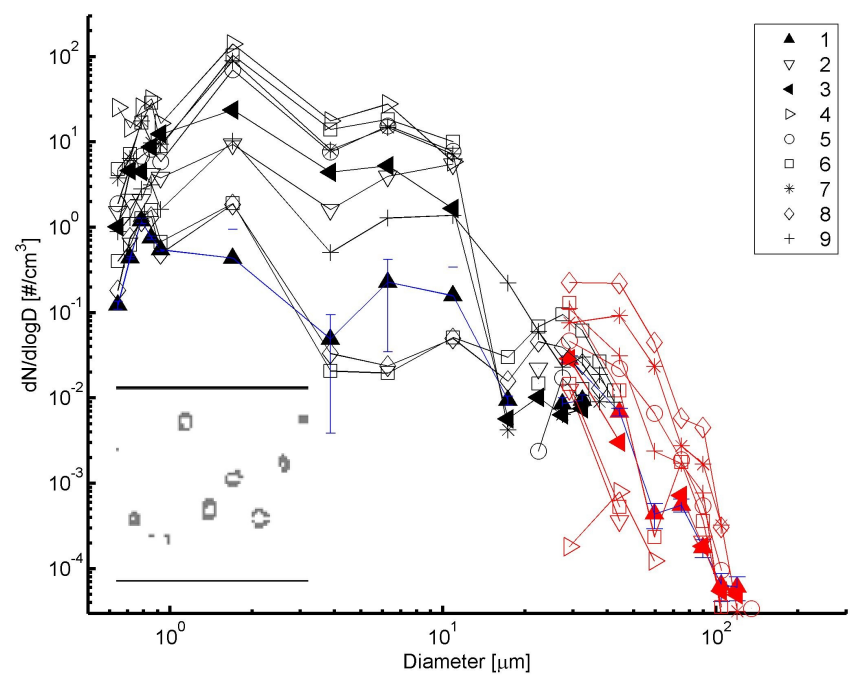

Fig. 3. Average particle size distribution $\mathrm{d} N / \mathrm{d} \log D_{\mathrm{p}}\left[\# / \mathrm{cm}^{3} / \mu \mathrm{m}\right.$ vs. maximum size in $\mu \mathrm{m}$ ] recorded over each verified orbit contrail pass during Flight B587 (pass number identified by the legend, cf. Table 1), for the CAS (black) and CIP-GS (red) probe. Error bars of one standard deviation are shown for pass 1 , error bars are much larger for those passes featuring concentrations $>50 \mathrm{~cm}^{-3}$ (see Table 1). CIP-GS images are shown from Pass 6.

A closer investigation into the particles sizes distributions (Fig. 4) and the $\mathrm{RH}_{\text {ice }}$ field showed that when higher $\mathrm{RH}_{\text {ice }}$ values were reported, particle size distributions reported by the CIP-GS probe tended to show higher number concentrations and larger particles. An exception to this is pass 3 which showed high RH, but a lower size distribution, this could be due to sampling the edge of the contrail rather than the centre.

This local change in $\mathrm{RH}$ will have a significant impact on the growth and evolution of the local ice crystal population in the emplaced orbit contrails. Highest RH was reported for orbit passes 3, 7 and 8. Pass 8 sampled the same section of contrail previously sampled in pass 4 (see Table 1). Peak CAS concentrations are much lower for pass 8 , but as revealed by the lidar plot, Fig. 7, during the over-flight the contrails were lowering over time due to large scale subsidence in the region.

An important point to note is that it is generally very difficult to determine the exact portion of a 3-dimensional contrail that is being sampled, i.e. whether at the edge or the centre of the contrails, where very different mixing regimes may alter the competition for any available water vapour by the growing ice crystals, or larger crystals may have fallen to lower levels. The CIP-GS and 2-D-C images recorded during these penetrations showed the ice crystal habits consisted of small plate-like crystals.

\subsubsection{Combined lidar and in situ detection from above contrail orbits}

Run 1 (from 16:05:35 to 16:17:39) was a SLR performed at an altitude of $10.3 \mathrm{~km}$, approximately $600 \mathrm{~m}$ above the level that the orbits formed between 15:13 and 15:32, Fig. 5 . Several increases in cloud particle number concentration (as measured by both CIP-GS and CAS), Fig. 6, coincided with the predicted orbit contrail locations from the NAME model, Fig. 5. These increases occurred at 16:11:00-16:12:30 (over the end of orbit 3, aged by $\sim 29 \mathrm{~min}$ ), and 16:14:20-16:17:00 (over dispersed orbits 2, 3 and 4, aged by up to $44 \mathrm{~min}$ ). The length of time a pass takes is dependent upon the spatial extent of the contrail and the orientation of the pass, i.e. whether perpendicular or at an angle to increase the time spent within the contrail.

The detection and scale of the contrail orbits was also confirmed by Lidar backscatter measurements (Fig. 7), and SWS measurements (Fig. 8a). Comparing the CIP-GS and CAS time series in Fig. 6 with the lidar data, we see good correspondence (where orbit contrail ice crystals were lifted to higher altitudes by local updrafts). The lidar also revealed the presence of contrails from other aircraft but these had not encroached into the orbit contrails at this stage. SWS spectra (nadir-facing geometry) for times during this Run (Fig. 8a) show clear differences in the magnitude and spectral shape for surface, cirrus and contrail measurements. Note the data shown in Fig. 8 have been normalised to 1.0, in order to show the differences in spectral shape more clearly. This obscures the observed factor of 4 increase between the contrail measurements and thick cirrus. There is clearly a significant difference in the shape of the spectra between the clear-sky, contrail cirrus and natural cirrus cases with contrail induced cirrus increasing the normalised radiances at wavelengths greater than $550 \mathrm{~nm}$, while thick naturally occurring cirrus has a significantly different spectral shape in normalised radiances with a reduction in radiance at wavelengths shorter than $400 \mathrm{~nm}$ and increased radiances at wavelengths longer than $400 \mathrm{~nm}$. The water absorption features centred around 950,1150 and $1400 \mathrm{~nm}$ also become much more evident. Potentially such differences could be used in discriminating between natural and contrail induced cirrus in future satellite algorithms.

The size distribution plots, Fig. 9, show the mean size distributions (from CIP-GS and CAS) for the overpasses. It can be seen that overpass 1 recorded slightly higher number concentrations for particles with diameter 6-20 $\mu \mathrm{m}$ compared to pass 2 , but otherwise the two size distributions were similar. CIP-GS images showed very small plate-like crystals although the exact habit is difficult to determine with the instruments used. 


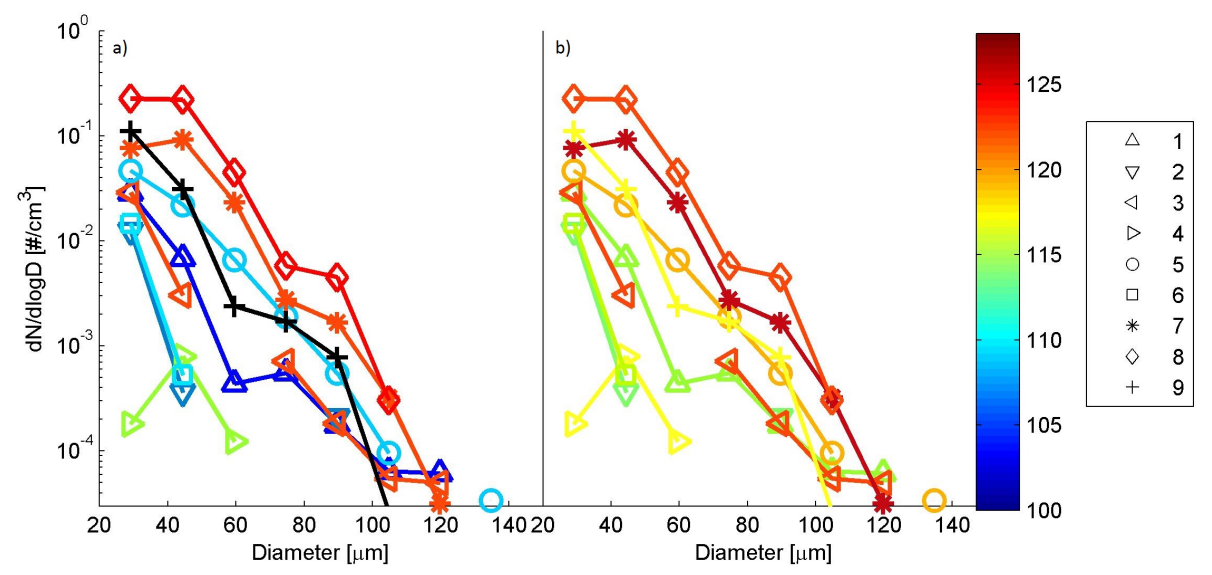

Fig. 4. Detail of Fig. 3 showing ice crystal size distribution (SD) recorded by the CIP-GS during contrail passes 1-9 in Flight B587. (a) SD coloured to ambient RH value when contrail was formed, (b) SD coloured to ambient RH value when contrail was sampled. Legend is given in the figure title, and lines are colours to the $\mathrm{RH}_{\text {ice }}(\%)$ scale shown on the right.

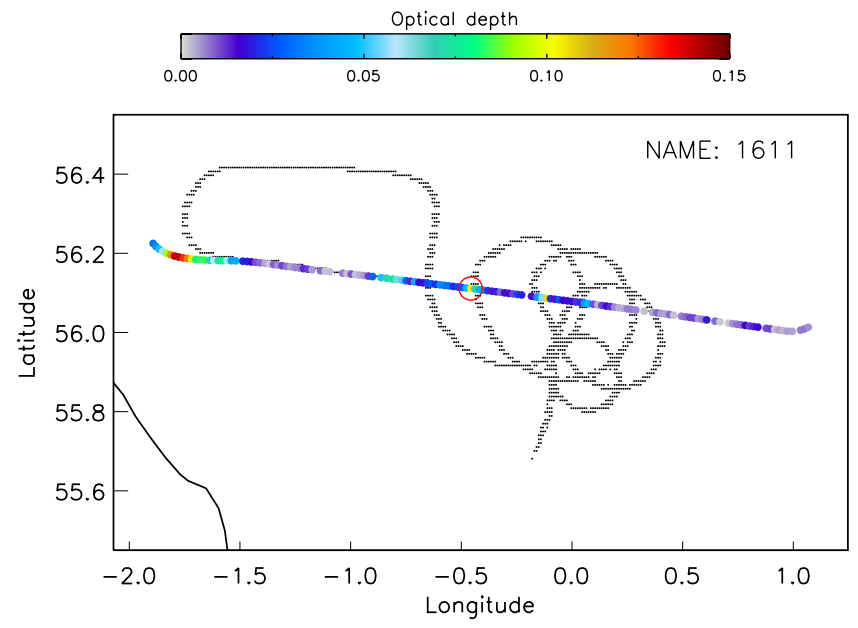

Fig. 5. Lidar-derived optical depth is shown by the colour variation (colour bar at top of figure) of the track going from east to west. The SLR passes over the previous orbits as indicated by the NAME data (dashed black line), where this is the output for 16:11 and the circle indicates the corresponding point on the SLR for this time.

\subsubsection{Detection of orbits from below}

Run 2 (16:23:32-16:38:00) was performed at $9.1 \mathrm{~km}$ from east to west directly under the previous run (Run 1). Figure 10 shows the increase in particle number concentration as the aircraft passes under the predicted orbit contrail positions, this was between 16:26:15-16:27:00 (the edge of orbit 2 contrail, aged by $\sim 60 \mathrm{~min}$ ) and then between 16:28:1016:30:10 (a mixture of dispersed orbit contrails 2 to 4 , and aged from between $\sim 45$ and $60 \mathrm{~min}$ ). These particles are likely the result of fall streaks from the orbit contrails, with $\mathrm{RH}_{\mathrm{ice}}<100 \%$ for most of this run. Evidence of fall streaks is also seen in Fig. 7. The increased concentrations recorded later on ( $\sim 16: 33$ to $16: 38)$ are associated with contrail ice particles formed during Run 1 (see Sect. 4.1.2) that have descended into the path of Run 2 (contrail age $\sim 20$ to $30 \mathrm{~min}$ ). CIP-GS images for these fall streaks again show plate like crystals, and were similar for both of these passes. Mean particle number size distribution and concentrations were similar for the earlier passes, with CIP-GS peak concentrations of 0.012 and $0.016 \mathrm{~cm}^{-3}$, respectively. Peak CAS concentrations were 0.6 and $0.7 \mathrm{~cm}^{-3}$, respectively, Fig. 10 .

SWS spectra (zenith view) for times noted here are shown in Fig. 8b (data has been normalised to 1.0). A significant $\left(4-7 \mathrm{~W} \mathrm{~m}^{-2} \mathrm{sr}^{-1}\right)$ difference in brightness and spectral shape between the contrails and clear sky was observed. As the contrail becomes more dispersed the spectral shape shifts becoming less bright (lower signal) between $\sim 340$ and $400 \mathrm{~nm}$, and more reflective (higher signal) between $\sim 450$ and $1300 \mathrm{~nm}$. This observed shift is consistent the increasing number of ice crystals measured by CIP and CAS as the contrail disperses. Under more ideal conditions the SWS data could be used to determine the radiative impact of contrail as it ages and spreads into cirrus. The data obtained here is in agreement with previous observations that contrails have a negative radiative forcing in the shortwave.

\subsubsection{Eastward-westward run sets}

Three pairs of eastward-westward runs (EWRs) were performed in the area at an altitude of $\sim 10 \mathrm{~km}$ later in the flight (east to west and reciprocals west to east). These were: Run 3 (eastward, 16:46:01-16:57:39) and Run 4 (westward, 17:05:22-17:15:33); Run 5 (eastward, 17:18:04-17:26:22) and Run 6 (westward, 17:31:17-17:39:56); Run 7 (eastward, 17:42:57-17:51:58) and Run 8 (westward, 17:56:3818:07:06). Some of these were revealed in the contemporaneous satellite imagery. In particular one of the complex turns between two runs, referred to as the "nappy-pin" manoeuvre 


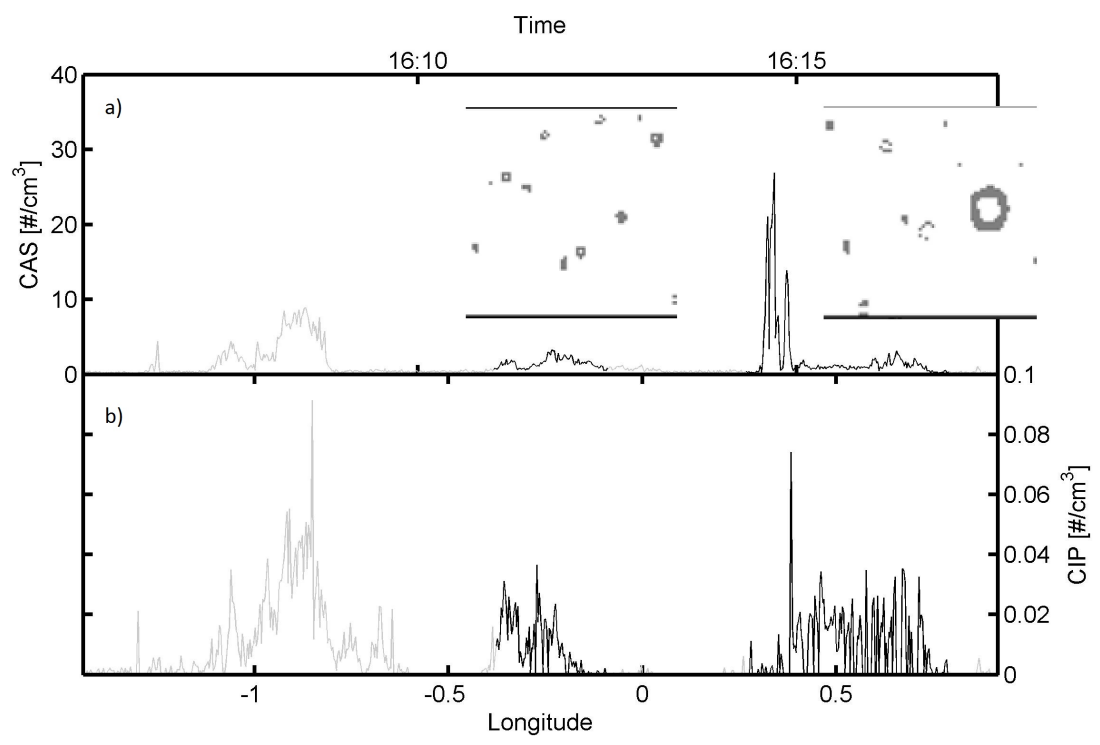

Fig. 6. Time series of (a) CAS number concentration and (b) CIP-GS number concentration for the SLR at higher altitudes (mean run temperature $-64^{\circ} \mathrm{C}$ ) passing over the orbit contrails. Where black data points indicate overpass times (see text). CIP-GS images corresponding to these overpass times are also shown.

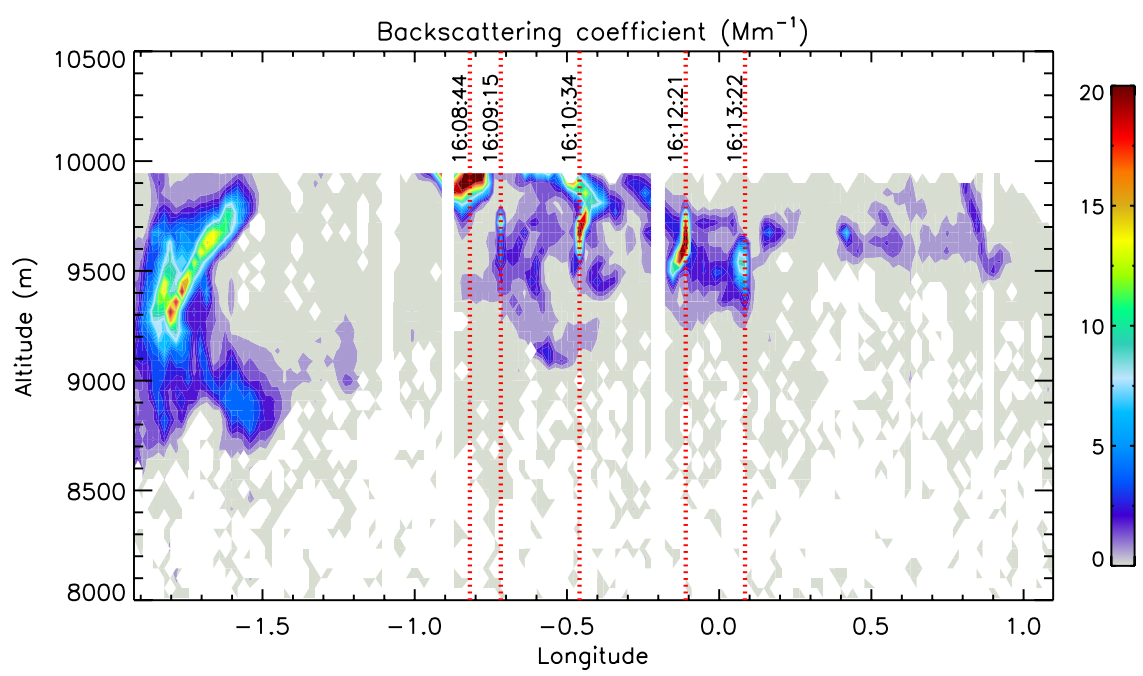

Fig. 7. Lidar-derived backscattering co-efficient (with marked contrail locations based on NAME model output) for the SLR (Run 1) at higher altitude from 16:03:00 to 16:18:35, contrail signals are noted between -1.0 and 0.5 degrees latitude, with earlier contrails detected further to the east. The larger signal on the left from $8600-10000 \mathrm{~m}$ shows a contrail from another aircraft.

in FAAM nomenclature can be seen, as illustrated by Fig. 11. This satellite image also shows that conditions were becoming much more difficult to work in, as mixed cirrus and contrails from other aircraft were present, together with midlevel clouds developing in the area. The purpose of the reciprocal runs was to firstly lay a contrail flying directly downwind and secondly to sample the persistent contrail on a reciprocal heading. Once again, the NAME model provided useful post-flight guidance.

Number concentration and $\mathrm{RH}$ values were found to vary together spatially. For the later runs RH was not any higher than encountered during the rest of the flight, yet number concentrations measured by the CIP-GS were distinctly higher. Here we were sampling cirrus that had formed in the area, or advected into the area during the flight (cirrus was noted as being present from $\sim$ 17:20 onwards). $\mathrm{NO}_{\mathrm{x}}$ data was not good enough to help with the analysis, and it is therefore not possible to distinguish between the spreading contrails and in-situ cirrus.

EWRs 3 and 4 were performed before cirrus affected the science area; time series data for these runs are shown in Fig. 12. Here the eastward part of the EWR is shown in black, 
a)

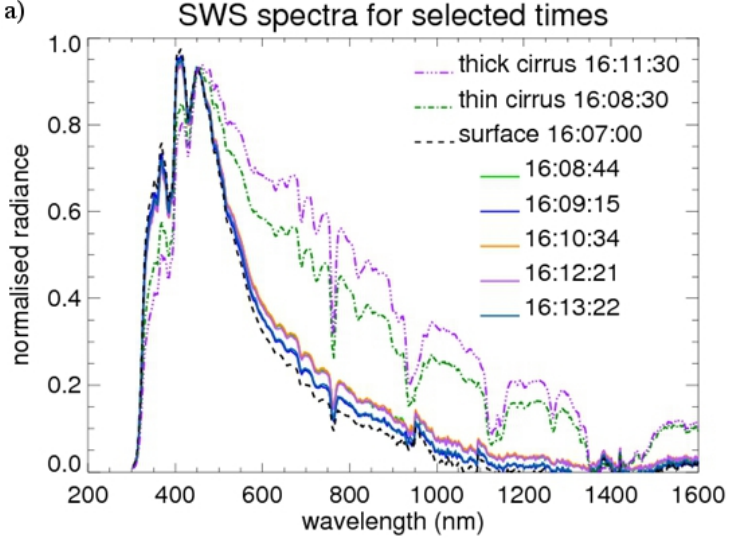

b)

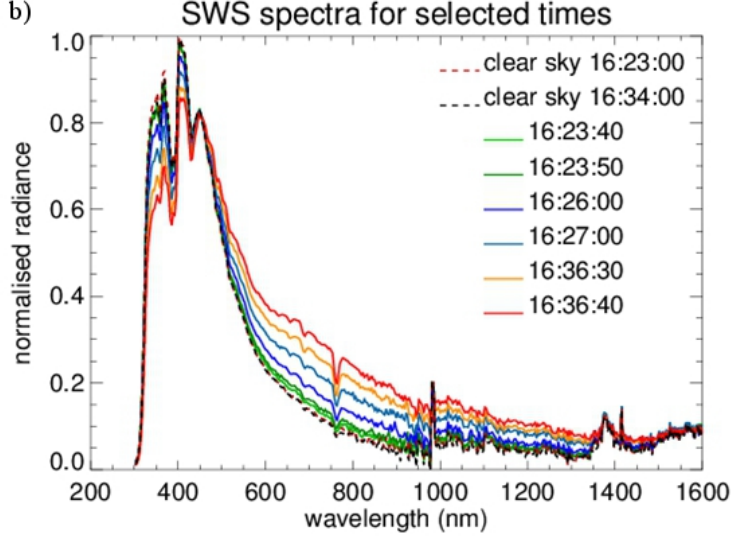

Fig. 8. (a) SWS (nadir geometry) spectra shown for the times during RUN 1 when contrails were sampled (solid lines) and for when cirrus was sampled (dashed lines). (b) SWS (zenith geometry) spectra shown for times during Run 2 when contrails were sampled (solid lines) and for when clear sky was sampled (dashed lines). Both plots are normalised to $450 \mathrm{~nm}$ wavelength.

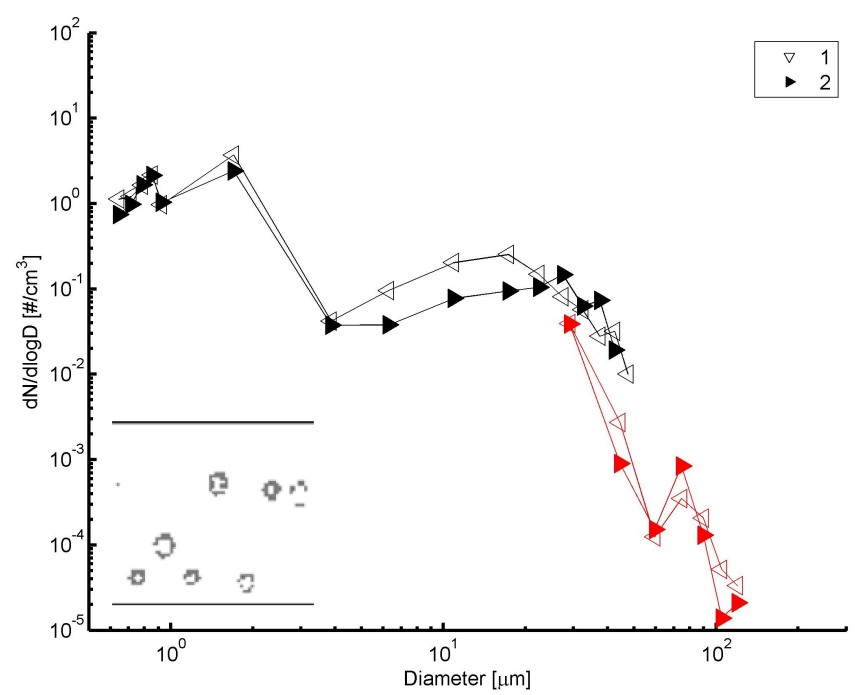

Fig. 9. Average particle size distribution $\mathrm{d} N / \mathrm{d} \log D_{\mathrm{p}}$ recorded during the overpass run (Run 1) for the CAS (black) and CIP-GS (red) probe. Legend denotes passes, times are indicated in the main text.

the westward part in green. Periods when NAME model outputs show we sample the eastward leg contrail ( 8 to $20 \mathrm{~min}$ old) during the reciprocal are indicated by the dashed boxesOn this occasion these locations and times overlap with the NAME predicted locations of signals seen during the eastward leg (as indicated by the arrows in Fig. 12). The NAME model outputs show that the orbits were possibly recorded on the turn to perform the reciprocal (red data points in Fig. 12), though the orbit contrails at this time would have been at least 60 min old and were not confirmed visually.

Although increases in concentration from the background level are seen at the same time for each of the probes shown in Fig. 12, the signals are not always synchronous, e.g. see the two red peaks between 1 and 0.5 longitudes where the peak show a similar magnitude for the CAS probe, but not for the CIP probe which measures particles in a different size range. This change in the measured concentrations for the different probes (which measure different size ranges) is indicative of the change in structure across a contrail edge and through different parts of the contrail. Images from the 2-D-C and CIP-GS probe reveal plate-like crystals dominate as before, though as we pass through the same contrails in the reciprocal run there is a shift towards there being larger particles. This is potentially an effect of the aircraft passing through the contrail on the eastward run and increasing the water vapour source, or the activation of a newer contrail on the eastward run. We tend to see more sharp number concentration increases on the CAS instrument during the return legs. Again this could be due to the formation of the newer contrail. When we pass through the region where the orbits were performed (60-100 min previously), CIP-GS images showed many very small particles $(D<30 \mu \mathrm{m})$, though these are counted in the smallest size bin that is not included in Fig. 12, as detailed in Sect. 2.2.

\subsubsection{Non-Bae-146 contrails measured during B587}

Non-FAAM aircraft contrails were detected prior to Run 1 (see lidar data in Fig. 7), with two strong contrails detected in the western section of the airspace sampled during this flight. They were sampled on several subsequent occasions e.g. during Run 1, during Run 2 (where fall streaks were observed), and several times in later runs. However only in Run 3 could they be pinpointed with any certainty (see the peaks at the western edge of Fig. 12a). The lidar detected these contrails at elevations between $10 \mathrm{~km}$ down to $8.5 \mathrm{~km}$ between 15:58-16:01 and 16:03-16:06. Run 1, 2, and 3 were performed at altitudes $10.4 \mathrm{~km}, 9.1 \mathrm{~km}$, and $10 \mathrm{~km}$, respectively. The age, aircraft origin or flight path orientation of these contrails is not known. These contrails are not visible 


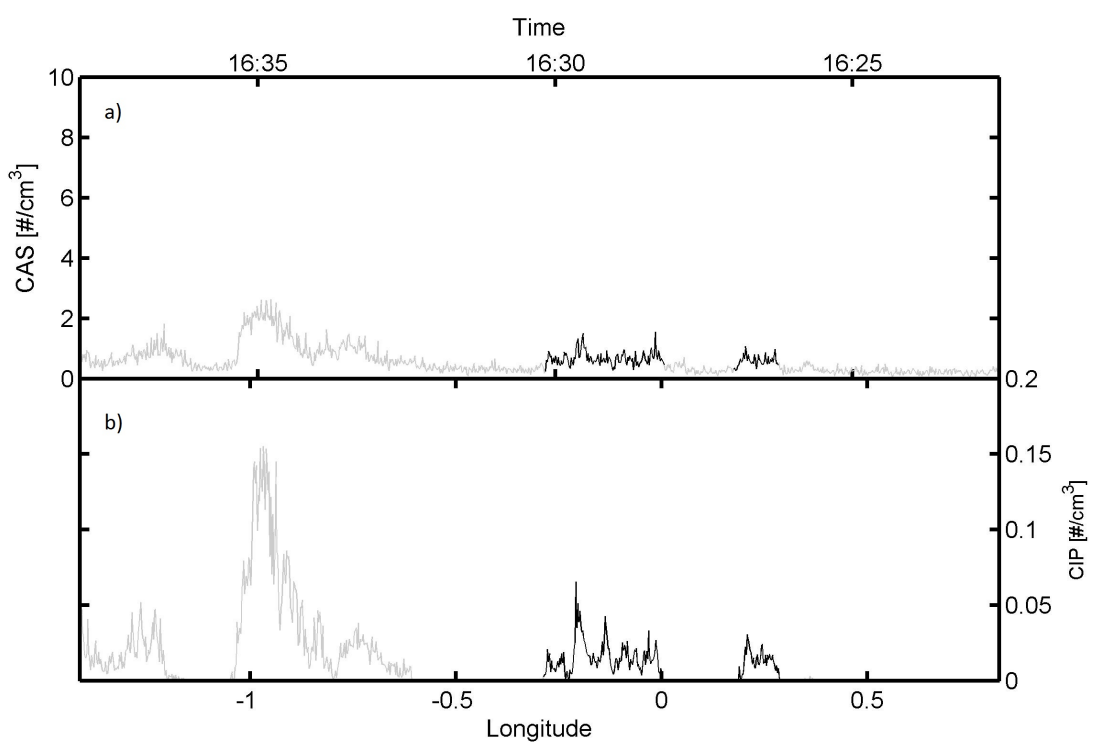

Fig. 10. Time series (from right to left) of CIP-GS and CAS number concentration for Run 2 (passing under orbits, mean temperature $=-54.6^{\circ} \mathrm{C}$ ). Contrail passes are indicated by the black data points (aircraft is flying from east to west), along with typical CIP-GS images from those times.

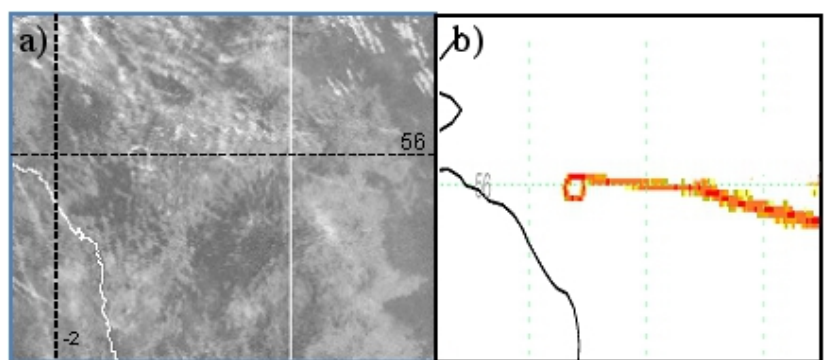

Fig. 11. (a) Satellite image (10.8-12.0 $\mu$ m product from NOAA 16 , overpass 18:23 UTC) from Flight B587, the North-East coast of England can be seen to the left of the image. 2. (b) the simulated contrail from the NAME simulations at 18:23 UTC.

in the available satellite images and so determining information regarding the ageing of these contrails is not possible. A table of "other" aircraft contrail passes is shown below, Table 2.

We may speculate that passes 12,15 and 18 are most likely to be measurements of the same contrail (as passes 15 and 18 were directly over pass 12 when advection is accounted for), but there is a vertical spacing of $1.2 \mathrm{~km}$ between the levels of these passes.

The younger phase of the contrail consisted of numerous small plate-like crystals with many crystals extending to larger sizes $(>100 \mu \mathrm{m})$, see Fig. 13. The larger ice crystals retained the hexagonal habit. Approximately $30 \mathrm{~min}$ later, the lower section of the contrail consisted of predominantly $(D<100 \mu \mathrm{m})$ plate-like crystals, with a shoulder appearing in the CAS size distribution at $\sim 50 \mu \mathrm{m}$, suggesting that
Table 2. "Other" aircraft contrail passes.

\begin{tabular}{lcrrc}
\hline Pass & Start time & End time & $\begin{array}{r}\text { Aircraft } \\
\text { altitude }[\mathrm{km}]\end{array}$ & $\begin{array}{c}\text { Temperature } \\
{\left[{ }^{\circ} \mathrm{C}\right]}\end{array}$ \\
\hline 10 & $15: 53: 30$ & $15: 55: 45$ & 9.7 & -59.4 \\
11 & $15: 57: 00$ & $15: 58: 45$ & 10.1 & -62.3 \\
$12^{*}$ & $16: 02: 30$ & $16: 03: 30$ & 10.3 & -62.7 \\
$13^{*}$ & $16: 07: 20$ & $16: 08: 50$ & 10.3 & -63.9 \\
14 & $16: 34: 00$ & $16: 35: 30$ & 9.1 & -54.2 \\
15 & $16: 36: 30$ & $16: 39: 00$ & 9.1 & -54.2 \\
16 & $16: 39: 45$ & $16: 40: 45$ & 9.2 & -54.4 \\
17 & $16: 41: 30$ & $16: 42: 30$ & 9.5 & -57.0 \\
18 & $16: 47: 00$ & $16: 47: 30$ & 10.0 & -61.4 \\
19 & $16: 48: 00$ & $16: 49: 30$ & 10.0 & -61.5 \\
20 & $16: 51: 00$ & $16: 53: 00$ & 10.0 & -61.5 \\
21 & $16: 55: 10$ & $16: 57: 00$ & 9.1 & -54.1 \\
\hline
\end{tabular}

* Contrails detected by lidar.

the smaller particles present earlier in the contrail started to grow once the initial larger particles had been removed by sedimentation. Ten minutes later, during pass 18 at around the same altitude as pass 12 , the CAS concentrations were higher, particularly for particles $>10 \mu \mathrm{m}$ in diameter, but the CIP concentrations were lower, suggesting the largest particles were being removed by sedimentation. This section serves to highlight the additional complication of other aircraft operating in the same airspace as the research aircraft, but also that, with additional information (e.g. age and source) for these contrails, further useful scientific data could be presented. 

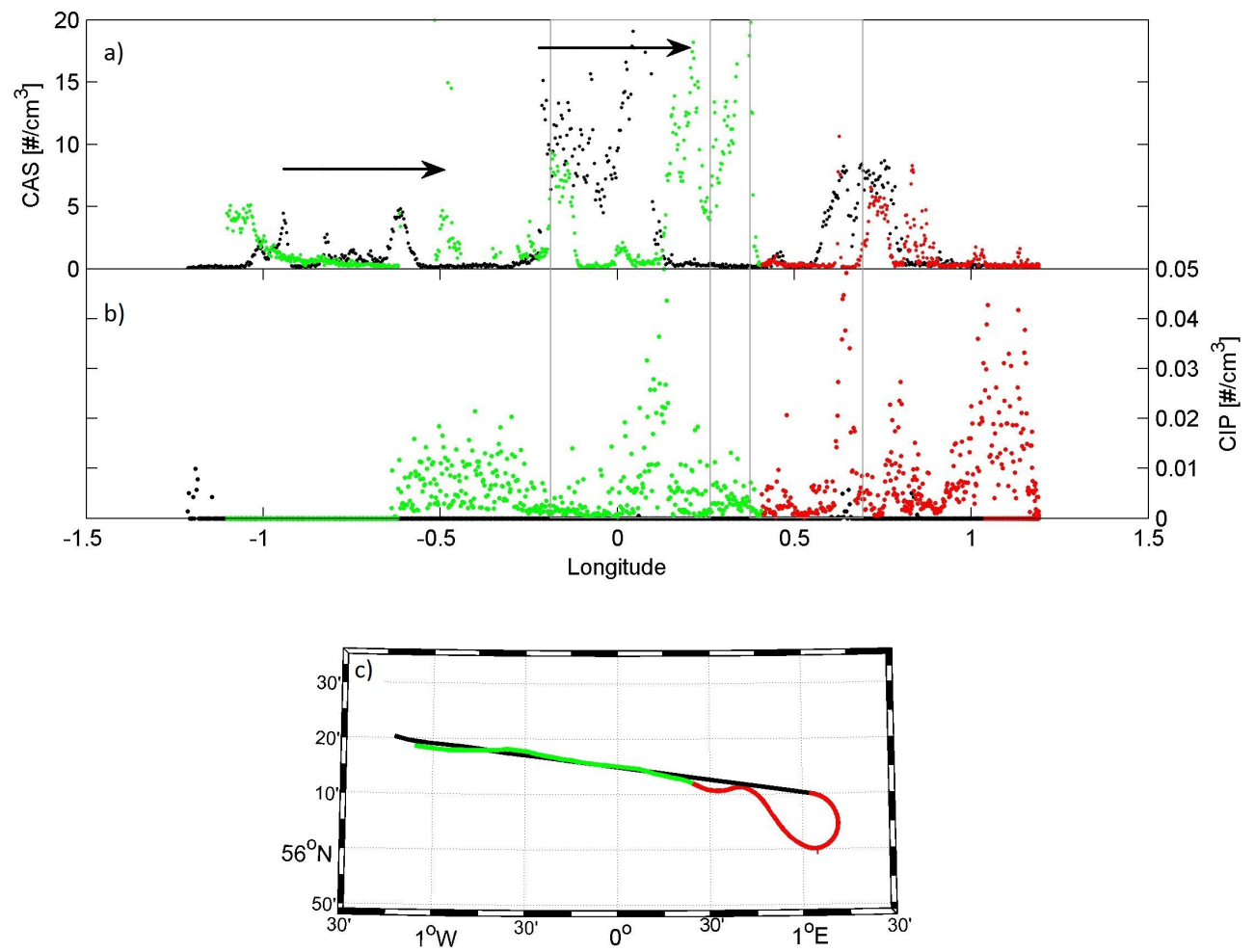

Fig. 12. (a) CAS number concentration, (b) CIP-GS number concentration and (c) the flight track for Run 3 (Black) and Run 4 (Green), mean temperature $=-61.7^{\circ} \mathrm{C}$, with additional between run data also shown (red). Grey dashed boxes indicate the longitude on the return leg where we sampled the outward leg (using NAME model output). Arrows indicate the location where increases seen on the outward leg (black) were expected to be on the return leg (using the NAME model).

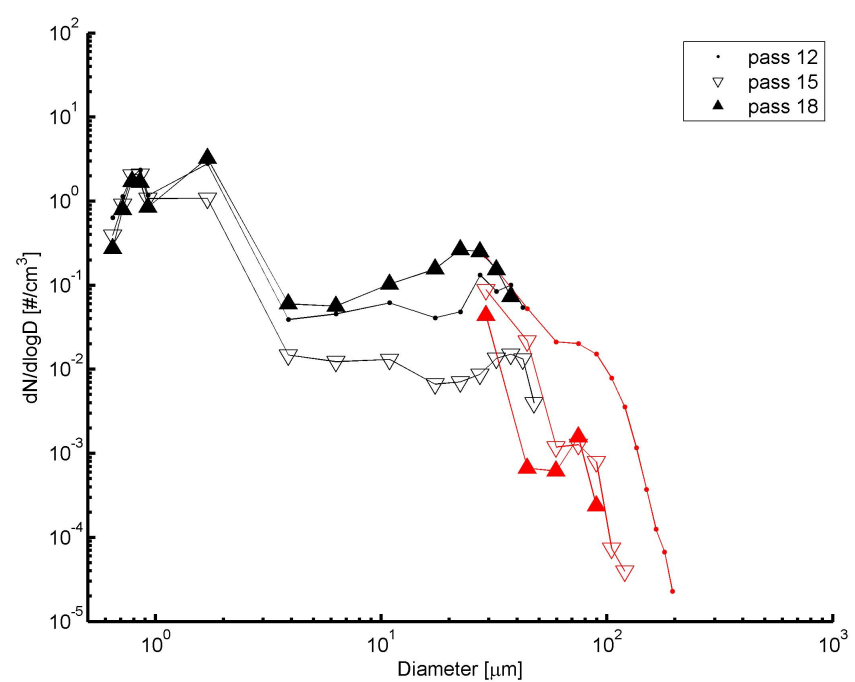

Fig. 13. Average CAS (black) and CIP-GS (red) particle size distributions for sampling of "other" aircraft contrails. Legend denotes passes, see main text for times.

\subsection{Determination of extinction co-efficient and ice water content}

The extinction coefficient, $\sigma$, was calculated from the in situ measured size spectrum as: $\sigma=\sum Q_{i} \pi R_{i}^{2} N_{i}$, where $N_{i}$ is the number density of particles in the size bin $i$, centered on radius $R_{i}$ (half the area equivalent diameter), and with extinction efficiency $Q_{i}$, where $Q_{i}$ is estimated using Mie scattering theory for spherical particles (Bohren and Huffman, 1998) at a wavelength of $500 \mathrm{~nm}$. In Fig. 14b the extinction coefficients for all measured particle sizes $(0.6$ to $900 \mu \mathrm{m})$ is shown in black, whereas the extinction from particles in the range $(0.6$ to $20 \mu \mathrm{m})$ is shown in red. The results in red are shown to allow comparison with the previous work published by Voigt et al. (2011), where they measured contrail ice particles in the vortex zone using a Forward Scattering Spectrometer Probe (FSSP).

As can be seen from Fig. 14b, for the full contrail passes dataset during flight B587, there is a wide spread in the derived extinction co-efficients. Closer investigation into the single contrail passes tells us more, as shown in Fig. 14c. The plot for period $X$ (orbit pass 8) shows a substantial difference in the probability distribution for the red and black lines, showing that care must be taken when comparing results with other work. When considering particles between 

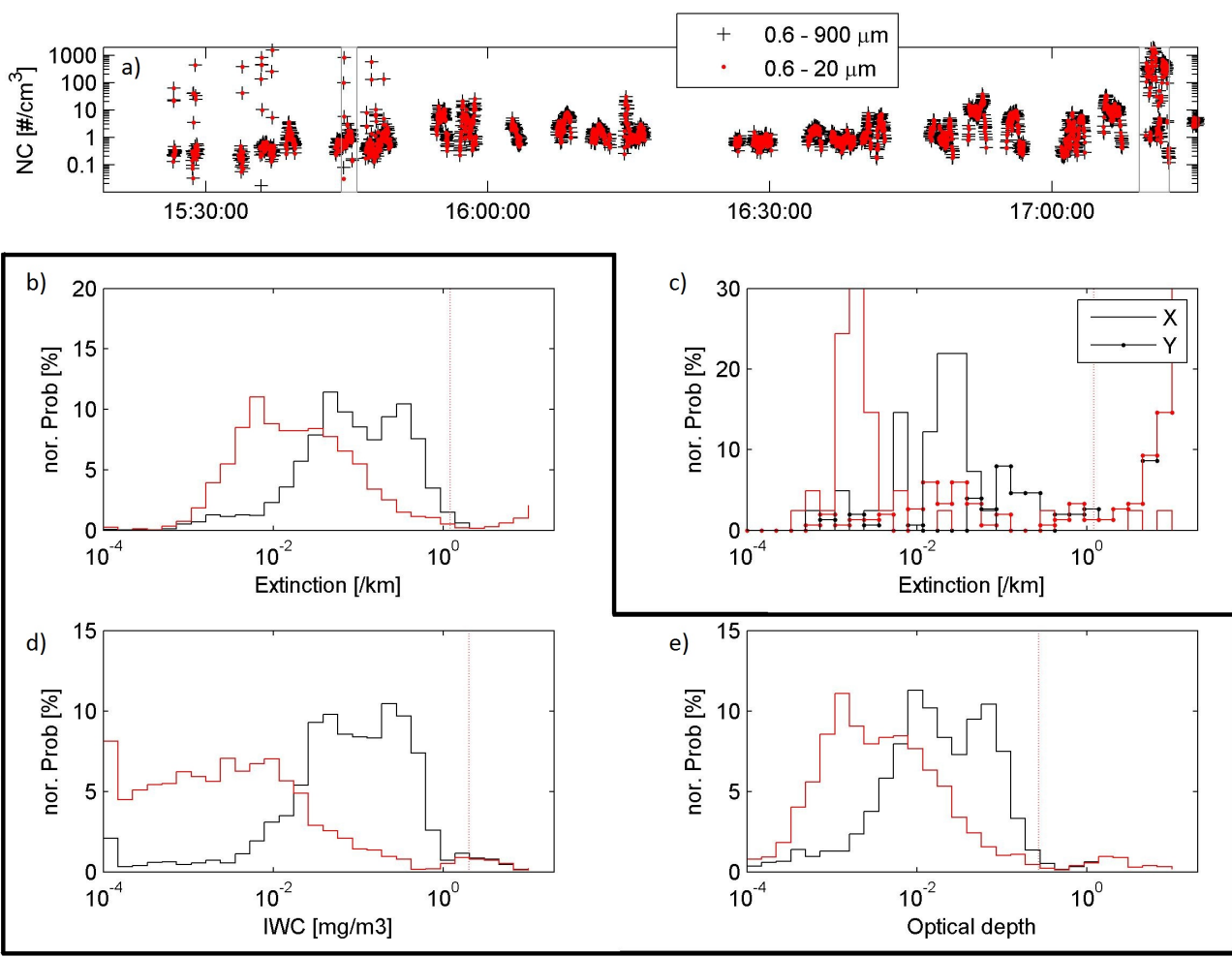

Fig. 14. (a) Time series of particle number concentration for all sizes (black: 0.6-900 $\mu \mathrm{m}$ ) and for sizes (red: 0.6-20 $\mu \mathrm{m}$ ), shown only for contrail sampling times. (b) Probability distribution of the extinction for all data points shown in (a), (c) Probability distribution of extinction for period $X$ (Pass 8 listed in Table 1 - solid lines) and for period $Y$ (the highest concentration sampled 17:10:00 to 17:12:30 - dot markers), both indicated in (a). (d) Probability distribution of the IWC for all data points shown in (a). (e) Probability distribution of the optical depth for all data points shown in (a), assuming a contrail thickness of $200 \mathrm{~m}$. Vertical red dashed lines show the mean values reported by Voigt et al. (2011).

0.6 and $20 \mu \mathrm{m}$, extinction peaks at $\sim 10^{-2} \mathrm{~km}^{-1}$, but for the total range measured using the CAPS instrument, the extinction peaks at $\sim 3 \times 10^{-2} \mathrm{~km}^{-1}$. On the occasions when there was a substantial increase in particle number concentration (period $Y$ ), the calculated extinction is much higher, as for the later pass shown in Fig. 14c. It is this pass that produces the small peak in the extinction probability at higher values in Fig. 14b.

Ice water content (IWC) was calculated from the CAPS size distribution measurements using the ice crystal massdiameter relationship of Brown and Francis (1995). Calculated values were of the order between 0.01 and $1 \mathrm{mg} \mathrm{m}^{-3}$, with a maximum value of $12.35 \mathrm{mg} \mathrm{m}^{-3}$ and a mean (median) of $0.16(0.01) \mathrm{mg} \mathrm{m}^{-3}$, a factor of ten lower than that reported by Voigt et al. (2011). The probability distribution of IWC values for all contrail pass data is shown in Fig. 14d. Also, assuming a contrail thickness of $200 \mathrm{~m}$ based on inflight observations and lidar data, we can estimate the contrail optical depth. The normalised probability distribution of the total contrail sampling optical depth is illustrated in Fig. $14 \mathrm{e}$ and has a mean (median) of 0.08 (0.002).

\section{Discussion}

In situ measurements of aircraft contrails are particularly difficult to perform, as is highlighted in this paper. Previous research in this field has mostly focussed on narrow lineshaped contrails. One of aviation's largest impacts is likely due to contrails contributing to cirrus initiation and then subsequent spreading and yet this effect remains largely unquantified (Forster et al., 2007). It is for these reasons that improved measurements and methodologies similar to those presented here, are required to increase the scientific understanding of contrail generation and evolution.

The pre-flight use of models providing ice supersaturation and cloud data over the UK and the surrounding area allowed more accurate planning of self-contrailing and sampling flight sorties in this case. The incorporation of lidar measurements into the experimental design also allowed in-flight assessment as to the location and spatial extent of the contrails that were being sampled; satellite images also provided additional information when available. Detailed cloud microphysics data were collected using several cloud probes (see Sect. 2), which combined, covered a size range from 1 to $960 \mu \mathrm{m}$. Post-flight, the advantage of using the Met Office 
NAME model for interpretation and verification was highlighted. This was used to determine which enhanced cloud particle number concentrations were due to the sampling of contrails made by the FAAM aircraft, and which were from other aircraft or cirrus encroaching into the sampling region. The combined use of the above allows us to report aerosol and cloud microphysics information for contrails of known age and it is expected that future experiments with more complete instrument suites (cloud microphysics probes covering a large size range and providing improved particle images; fast response aerosol particle counters and composition measurements; fast response trace gas measurements; lidar and radiometers for remote sensing) would be a benefit for future studies using this approach.

An overview of previous contrail measurements has been outlined in Heymsfield et al. (2010), though comparison with their results and previous studies must be performed with care, as the conditions and approaches used for past measurements vary widely, with most measurements being taken whilst travelling along very young contrails, often near the vortex phase by chase aircraft (close to the contrailing aircraft). The results shown in this current study more closely resemble those from the Goodman et al. (1998) study. We note little or no change in ice crystal habit/size towards the periphery of the contrail, and that the majority $(\sim 80 \%)$ of detected ice particles have hexagonal habits (where the observed habits of smaller ice crystals were ambiguous due to the available detection technique), similar to what Goodman et al. (1998) reported. We also come to the same conclusion as Baumgardner and Gandrud (1998), namely that the growth of ice crystals is inhibited by a limited water vapour supply. Additional previous studies that include information regarding ice crystal habits report varying results: e.g. Febvre et al. (2009) reported quasi-spherical ice crystals in young contrails that became increasingly non-spherical as the contrails aged and Bailey and Hallet (2004) reported laboratory freezer grown crystals of $150-300 \mu \mathrm{m}$ at $-70{ }^{\circ} \mathrm{C}$ and $25 \%$ $\mathrm{SS}_{i}$ having habits that were mainly columnar, needles, bullet rosettes and irregular shapes. Yang et al. (2010) and Rap et al. (2010b) show that, in addition to ice crystal size, ice crystal shape is an important component in determining the contrail radiative impact. We note from these findings that simultaneous $\mathrm{RH}_{\text {ice }}$ measurements covering the full spatial advection range of the contrail plume are required to correctly interpret the growth processes occurring and assess in situ measurements.

Voigt et al. (2011; using FSSP, 2-D-C, CIP, CPI, sampling behind contrailing aircraft) being a more recent study on contrails, used a combination of cloud microphysical probes. They sampled a variety of contrails, from several aircraft, of various ages (1-10 min) and under varying conditions ( -60 to $-44^{\circ} \mathrm{C}, 122$ to $55 \% \mathrm{RH}$ ). They reported mean ice crystal number densities of $125 \mathrm{~cm}^{-3}$ with mean diameter $\sim 5 \mu \mathrm{m}$. They also show the probability distribution of calculated extinction values (using FSSP data, particle sizes
$0.39-17.7 \mu \mathrm{m})$ that peak $\sim 1 \mathrm{~km}^{-1}$, with a secondary smaller peak $\sim 2 \times 10^{-2} \mathrm{~km}^{-1}$, mean values are marked on Fig. $14 \mathrm{~b}$. In earlier experiments, Gayet et al. (2006) report mean extinction co-efficients, as measured by a polar nephelometer, between 0.07 (thin cirrus) and $5.34 \mathrm{~km}^{-1}$ (wave cloud). In our study we find mean extinction co-efficient values of $41[0.01]_{0.002}^{0.10} \mathrm{~km}^{-1}$ (shown as mean[median $]_{25 \text { th percentile) }}^{75 \text { th }}$. Whilst the results from this recent study are within the range of previous studies we typically do not see the higher concentrations $\left(>100 \mathrm{~cm}^{-3}\right)$ of ice crystals that are measured in the vortex phase of a young contrail. As a result, we obtain lower extinction coefficients compared with studies that have sampled the contrail in the early phase (when considering a similar particle size range), indicating that extinction, optical depth and also IWC (see Fig. 14) may decrease as the contrails evolve. The probability distributions shown in Fig. 14 show the variability of the observed contrails, and also that including measurements over a wider microphysical size range are needed to obtain more accurate characterisation of the extinction, IWC and optical depth properties of contrails. This is illustrated by comparing the two quite different results obtained for extinction, depending on whether data from over the complete measured size range was used, or whether data from a size range limited to the smaller particles (for comparison with Voigt et al., 2011) were used.

SWS data show that contrails have a clearly measureable radiative affect (Fig. 8), particularly in the short-wave between $\sim 300$ and $400 \mathrm{~nm}$ (Fig. 8b: zenith data) and between $\sim 450$ and $1000 \mathrm{~nm}$. It is likely that the small shifts observed in the zenith data are from an increase in ice crystal concentration; however spectral shifts observed in nadir views are inconclusive. This is due to the lack of simultaneous in situ microphysical data, preventing a determination of whether the spectral shift is due to changes in crystal size/habit or changes in optical depth effects. In addition, as the optical depths are low and it is difficult to separate the contributions due to the measured radiances from the contrail induced cirrus and from the surface. For this reason zenith viewing geometry is preferable for determining the radiative impact of contrail induced cirrus.

In addition to microphysical and radiative properties of contrails past studies have outlined the importance of soot particles for the control of ice formation in contrails (e.g. Kärcher and Yu, 2009; Hong et al., 2008; Petzold et al., 1998); in addition to the potential role of soot forming cirrus ice crystals downstream or after dissolution of short lived contrails. This will form the focus of further studies using the methodology described here using black carbon aerosol spectrometers, e.g. McMeeking et al. (2010).

The methodology described in this paper aimed to collect microphysical and radiative data from contrails formed and sampled by instruments aboard the FAAM research aircraft, in a model-forecasted cloud free supersaturated region. Forecast models were thus found to be useful for choosing flight 
areas, as in this and other case studies undertaken within COSIC. The area flown in in this case was supersaturated and initially free from cloud allowing easier interpretation of the measurements. We have shown that on-board lidar measurements are also extremely useful for determining the spatial extent of the contrails being sampled, as well as showing when aged contrails merge or move into regions where background cirrus is present.

For the case study presented, meteorological conditions on the day meant that the atmosphere was initially too dry to allow contrail ice crystals to grow to larger sizes or to be visually detectable for longer than $\sim 40 \mathrm{~min}$, and later on cirrus cloud encroached on the area, making sampling difficult due to the high background concentrations of cloud particles. However, there are several experimental limitations to this approach, (e.g. Schröder et al., 2000). A common issue with contrail measurements is that contrails older than a few minutes are difficult to sample, as even if visible from below or aloft, they are in most cases difficult to recognise when at the same altitude as the aircraft. A similar issue is the inhomogeneity of the contrails, which again cannot be seen whilst in-situ. Additional experimental limitations also include poor sampling statistics for larger crystals $(>100 \mu \mathrm{m})$ and small sampling times if sampling across contrails rather than travelling along a contrail for an extended period. Due to known issues with certain cloud probes regarding inlet shattering of larger cloud particles (Korolev et al., 2011), care should also be taken when using data from previous studies where larger ice particles were present. The use of several probes to cover a wide size range, as is the case here, is recommended for use in parameterisation developments.

Despite the limitations of the present case study, we submit that under favourable atmospheric conditions such that longlived contrails are formed, the methodology described here, with additional in situ measurements could provide the much needed contrail data for improved parameterisation of contrail evolution. It is important that subsequent investigations into contrails make full use of available supporting data, e.g. lidar and radiation instrumentation. We suggest the use of two aircraft in future experiments: one flying at contrail altitude with meteorological and environmental state parameter measurements, as well as aerosol and cloud microphysics instrumentation, and a second aircraft at a higher or lower altitude, fitted with remote sensing equipment as described here, and following the methodology described by Dickinson et al. (2011), to fully characterise the contrail spatial extent and environment. This would also allow a more thorough characterisation and investigation of microphysical changes affecting radiative measurements due to external influences, and provide information regarding the inhomogeneity of the contrails. This would lead to an improved ability to determine which portion of a contrail was being sampled at any one time. A ground based lidar may also serve the same purpose, and enable a better determination of the age and evolution of the sampled contrails. A second higher aircraft could also provide real-time information to guide the sampling of the contrails by the in situ aircraft (if formed during the observation period). This outlined method could be used to bridge the gaps in our knowledge of contrail microphysics.

\section{Conclusions}

This paper outlines a methodology for successful sampling and interpretation of contrail microphysical and radiative data.

Forecast models were used to find regions of airspace that would be ideal (i.e. cloud free with high ice supersaturation) for contrail formation and sampling. Contrails were then formed in a distinctive pattern and sampled by the FAAM BAe-146 research aircraft both in situ using cloud microphysics probes and remotely using lidar and SWS.

Despite the difficulties involved with performing these types of experiments, contrails were sampled at various ages from $7 \mathrm{~min}$ to over an hour old. The UK Met Office NAME model was found to be an extremely useful tool for determining contrail location and age.

Number concentrations were found to be lower than in previous studies where sampling was done closer to the source aircraft. Size distribution information shows ice crystals typically $\sim 10 \mu \mathrm{m}$ in size (no change at the contrail periphery was noted), with an increase in size and number of particles typically seen for passes where higher RH (>120\%) was noted, thus illustrating the impact of environmental supersaturation gradients on contrail development and the need for high resolution measurements of this type. Results have also shown that for more reliable extinction, optical depth and ice water content reported values, the complete ice particle number size distribution is necessary and this is accomplished by the use of more than one microphysical probe. The available image data from the 2-D-C and CIP-GS show plate-like ice crystal habits and it is thought that a lack of water vapour results in ice crystals being unable to grow to more cirrus-like (rosette) ice crystals; this is also thought to be why we see a contrail lifetime of $\sim 40 \mathrm{~min}$.

Lidar and SWS were able to successfully detect the contrails from higher altitude, where the lidar was very useful for in-flight determination of the advection and spatial extent of the contrails. Fall streaks were noted, and were subsequently sampled on a lower altitude run. Later runs at contrail altitude are very difficult to interpret due to cirrus encroaching into the science area; matching NAME data to contrail passes becomes difficult without additional supporting data (e.g. high resolution $\mathrm{NO}_{\mathrm{x}}$ data).

The limited results in this paper show the complexity of contrail evolution as well as the difficulty in performing in situ measurements, due both to the variability of the contrails (dependent on their environment), and also the difficulty in determining what part of a 3-D contrail has been sampled (central region, edges or fall streaks). In this case, maximum 
concentrations of ice particles and 3-D dispersion modelling assisted with this identification process, though this information can only be provided post-flight. The approach demonstrated here and the data obtained using this method can be used to help build a physically based parameterisation of contrail spreading into cirrus and will prove useful for successive studies. Improvements to the current method, such as the use of two aircraft to provide simultaneous radiation and microphysical data would allow a reduction in some of the current uncertainties of parameterisations. Consideration should also be given to the exhaust properties of the aircraft producing the contrails.

Further experiments are needed, complete with the additional support of e.g. up or downward pointing lidars, models and satellite products, for a range of temperature and saturation conditions to collate a suitable database with sufficient statistical robustness to address climatology needs.

Acknowledgements. This work was funded by the Natural Environment Research Council (NERC), grant reference: NE/G00479X/1. Airborne data were obtained using the BAe-146-301 Atmospheric Research Aircraft (ARA) flown by Directflight Ltd and managed by the Facility for Airborne Atmospheric Measurements (FAAM), which is a joint entity of the Natural Environment Research Council [NERC] and the Met Office. Acknowledgement is made to the Facility for Ground-based Atmospheric Measurement (FGAM), National Centre for Atmospheric Science (NCAS) for the provision and operation of cloud spectrometer and software analysis tools. Thanks to Armin Afchine (Institute for Energy and Climate Research, IEK-7) for help with CAPS data.

The UK Met Office provided NAME model results (special thanks to Robert Thorpe) for the COSIC project. Aircraft data and Satellite images were obtained via the British Atmospheric Data Centre (BADC), the NERC designated data centre.

Edited by: A. Petzold

\section{References}

Bailey, M. and Hallett, J.: Growth rate and habits of ice crystals between $-20^{\circ}$ and $-70^{\circ} \mathrm{C}$, J. Atmos. Sci., 61, 514-544, 2004.

Baumgardner, D. and Gandrud, B. E.: A comparison of the microphysical and optical properties of particles in an aircraft contrail and mountain wave cloud, Geophys. Res. Lett. 25, 1129-1132, doi:10.1029/98GL00035, 1998.

Baumgardner, D., Jonsson, H., Dawson, W., Connor, D. O., and Newton, R.: The cloud, aerosol and precipitation spectrometer (CAPS): A new instrument for cloud investigations, Atmos. Res., 59-60, 251-264, 2001.

Baumgardner, D., Brenguier, J. L., Bucholtz, A., Coe, H., DeMott, P. J., Garrett, T. J., Gayet, J. F., Hermann, M., Heymsfield, A., Korolev, A., Krämer, M., Petzold, A., Strapp, W., Pilewskie, P., Taylor, J., Twohy, C., Wendisch, M., Bachalo, W., and Chuang, P.: Airborne instruments to measure atmospheric aerosol particles, clouds and radiation: A cook's tour of mature and emerging technology, Atmos. Res., 102, 10-29, 2011.
Bohren, C. F. and Huffman, D. R.: Absorption and Scattering of Light by Small Particles, 544, ISBN:0471293407, Wiley-VCH, Weinheim, Germany, 1998.

Boucher, O.: Atmospheric science: Seeing through contrails, Nature Climate Change, 1, 24-25, doi:10.1038/nclimate1078, 2011.

Brown, P. D. A. and Francis, P. N.: Improved measurements of the ice water content in cirrus suing a total-water probe, J. Atmos. Ocean. Technol., 12, 410-414, 1995.

Burkhardt, U. and Kärcher, B.: Global radiative forcing from contrail cirrus, Nature Climate Change, 1, 54-58, doi:10.1038/nclimate1068, 2011.

Burkhardt, U., Kärcher, B., and Schumann, U.: Global modelling of the contrail and contrail cirrus climate impact, B. Am. Meteor. Soc., 91, 479-483, doi:10.1175/2009BAMS2656.1, 2010.

Crosier, J., Bower, K. N., Choularton, T. W., Westbrook, C. D., Connolly, P. J., Cui, Z. Q., Crawford, I. P., Capes, G. L., Coe, H., Dorsey, J. R., Williams, P. I., Illingworth, A. J., Gallagher, M. W., and Blyth, A. M.: Observations of ice multiplication in a weakly convective cell embedded in supercooled mid-level stratus, Atmos. Chem. Phys., 11, 257-273, doi:10.5194/acp-11-257-2011, 2011.

Dickinson, C., Komguem, L., Whiteway, J. A., Illnicki, M., Popovici, V., Junkermann, W., Connolly, P., and Hacker, J.: Lidar atmospheric measurements on Mars and Earth, Planet. Space Sci., 59, 942-951, 2011.

Febvre, G., Gayet, J.-F., Minikin, A., Schlager, H., Shcherbakov, V., Jourdan, O., Busen, R., Fiebig, M., Kärcher, B., and Schumann, U.: On optical and microphysical characteristics of contrails and cirrus, J. Geophys. Res., 114, D02204, doi:10.1029/2008JD010184, 2009.

Fernald, F. G.: Analysis of atmospheric lidar observations: Some comments, Appl. Opt., 23, 652-653, 1984.

Field, P. R., Heymsfield, A. J., and Bansemer, A.: Shattering and particle interarrival times measured by optical array probes in ice clouds, Atmos. Ocean. Technol., 23, 1357-1371, 2006.

Forster, P. M., Ramaswamy, R., Artaxo, P., Bernsten, T., Betts, R., Fahey, D. W., Haywood, J., Lean, J., Lowe, D. C., Myhre, G., Nganga, J., Prinn, R., Raga, G., Schulz, M., and Van Dorland, R.: Changes in Atmospheric Constituents and in Radiative Forcing, in: Climate Change 2007: The Physical Science Basis. Contributions of Working Group I to the Forth Assessment of the Intergovernmental on Climate Change, edited by: Soloman, S., Qin, D., Manning, M., Chen, Z., Marquis, M., Averyt, K. B., Tignor, M., and Miller, H. L., Cambridge University Press, United Kingdom and New York, NY, USA, 2007.

Fuglestvedt, J., Berntsen, T., Myhre, G., Rypdal, K., and Skeie, R. B.: Climate forcing from the transport sectors, P. Natl. Acad. Sci. USA, 105, 454-458, doi:10.1073/pnas.0702958104, 2008.

Gayet, J.-F., Shcherbakov, V., Mannstein, H., Minikin, A., Schumann, U., Ström, J., Petzold, A., Ovarlez, J., and Immler, F.: Microphysical and optical properties of midlatitude cirrus clouds observed in the southern hemisphere during INCA, Q. J. Roy. Meteorol. Soc., 132, 2719-2748, doi:10.1256/qj.05.162, 2006.

Goodman, J., Pueschel, R. F., Jensen, E. J., Verma, S., Ferry, G. V., Howard, S. D., Kinne, S. A., and Baumgardner, D.: Shape and size of contrails ice particles. Geophys. Res. Lett., 25, 13271330, 1998.

Haywood, J. M., Allan, R. P., Bornemann, J., Forster, P. M., Francis, P. N., Milton, S., Rädel, G., Rap, A., Shine, K. P., and Thorpe, R.: 
A case study of the radiative forcing of persistent contrails evolving into contrail-induced cirrus, J. Geophys. Res., 114, D24201, doi:10.1029/2009JD012650, 2009.

Heymsfield, A. J., Lawson, R. P., and Sachse, G. W: Growth of ice crystals in a precipitating contrail, Geophys. Res. Lett., 25, 13351338, 1998.

Heymsfield, A. J., Baumgardner, D., DeMott, P., Forster, P., Gierens, K., and Kärcher, B.: Contrail Microphysics, B. Am. Meteor. Soc., 91, 465-472, doi:10.1175/2009BAMS2839.1, 2010.

Hong, G., Feng, Q., Yang, P., Kattawar, G. W., Minnis, P., and Hu, Y. X.: Optical properties of ice particles in young contrails. Journal of Quant. Spectrosc. Ra., 109, 2635-2647, 2008.

Johnson, B., Turnbull, K., Dorsey, J., Baran, A., Ulanowski, Z., Hesse, E., Cotton, R., Brown, P., Burgess, R., Capes, G., Webster, H., Wooley, A., Rosenburg, P., and Haywood, J. M.: In-situ observations of volcanic ash clouds from the FAAM aircraft during the eruption of Eyjafjallajökull in 2010, J. Geophys. Res., 117, D00U24, doi:10.1029/2011JD016760, 2012.

Jones, A. R., Thomson, D. J., Hort, M., and Devenish, B.: The U.K. Met Office's next-generation atmospheric dispersion model, NAME III, in: Air Pollution Modeling and its Application XVII (Proceedings of the 27th NATO/CCMS International Technical Meeting on Air Pollution Modelling and its Application), edited by: Borrego, C. and Norman, A.-L., Springer, 580-589, 2007.

Kärcher, B.: Aviation-produced aerosols and contrails, Surv. Geophys., 20, 113-167, doi:10.1023/A:1006600107117, 1999.

Kärcher, B. and Yu, F.: Role of aircraft soot emissions in contrail formation, Geophys. Res. Lett., 36, L01804, doi:10.1023/A:1006600107117, 2009.

Kärcher, B., Peter, Th., Biermann, U. M., and Schumann, U.: The Initial composition of jet condensation trails, J. Atmos. Sci., 53, 3066-3083, 1996.

Klett, J. D.: Lidar inversion with variable backscatter/extinction ratios, Appl. Optics, 24, 1638-1643, 1985.

Knollenberg, R. G.: The optical array: An alternative to scattering or extinction for airborne particle size determination, J. Appl. Meteor., 9, 86-103, 1970.

Knollenberg, R. G.: Measurements of the growth of the ice budget in persisting contrail, J. Atmos. Sci., 29, 1367-1374, 1972.

Korolev, A. V., Emery, E. F., Strapp, J. W., Cober, S. G., Isaac, G. A., Wasey, M., and Marcotte, D.: Small ice particles in tropospheric clouds: Fact or artefact? Airborne icing instrumentations evaluation experiment, Bull. Amer. Soc., 92, 967-973, doi:10.1175/2010BAMS3141.1, 2011.

Lawson, R. P., Heymsfield, A. J., Aulenback, S. M., and Jensen, T. L.: Shapes, sizes and light scattering properties of ice crystals in cirrus and a persistent contrail during SUCCESS, Geophys. Res. Lett., 25, 1331-1334, doi:10.1029/98GL00241, 1998.

Lee, D. S., Fahey, D. W., Forster, P. M., Newton, P. J., Wit, R. C. N., Lim, L. L., Owen, B., and Sausen, R.: Aviation and global climate change in the 21st century, Atmos. Environ., 43, 35203537, doi:10.1016/j.atmosenv.2009.04.024, 2009.

Marenco, F., Johnson, B., Turnbull, K., Newman, S., Haywood, J. M., Webster, H., and Ricketts, H.: Airborne lidar observations of the 2010 Eyjafjallajökull volcanic ash plume, J. Geophys. Res., 116, D00U05, doi:10.1029/2011JD016396, 2011.

McFarquhar, G. N., Um, J., Freer, M., Baumgardner, D., Kok, G. L., and Mace, G.: Importance of small ice crystals to cirrus properties: Observations from the Tropical Warm Pool International
Cloud Experiment (TWP-ICE), Geophys. Res. Lett., 34, L13803, doi:10.1029/2007GL029865, 2007.

McMeeking, G. R., Hamburger, T., Liu, D., Flynn, M., Morgan, W. T., Northway, M., Highwood, E. J., Krejci, R., Allan, J. D., Minikin, A., and Coe, H.: Black carbon measurements in the boundary layer over western and northern Europe, Atmos. Chem. Phys., 10, 9393-9414, doi:10.5194/acp-10-9393-2010, 2010.

Petzold, A., Busen, R., Schröder, F. P., Baumann, R., Kuhn, M., Ström, J., Hagen, D., Whitefield, P., Baumgardner, D., Arnold, F., Borrmann, S., and Schumann, U.: Near field measurements on contrail properties from fuels with different sulfur content, J. Geophys. Res., 103, 29867-29880, 1997.

Petzold, A., Ström, J., Ohlsson, S., and Schröder, F. P.: Elemental composition and morphology of ice-crystal residual particles in cirrus clouds and contrails, Atmos. Res., 49, 21-34, 1998.

Petzold, A., Fiebig, M., Flentje, H., Keil, A., Leiterer, U., Schröder, F., Stifter, A., Wendisch, M., and Wendling, P.: Vertical variability or aerosol properties observed at a continental site during LACE 98, J. Geophys. Res., 107, 8128, doi:10.1029/2001JD001043, 2002.

Poellot, M. R., Arnott, W. P., and Hallett, J.: In situ observations of contrail microphsyics and implications for their radiative impact, J. Geophys. Res., 104, 12077-12084, 1999.

Rädel, G. and Shine, K. P.: Validating ECMWF forecasts for the occurrence of ice supersaturation using visual observations of persistent contrails and radiosonde measurements over England, Q. J. Roy. Meteorol. Soc., 136, 1723-1732, 2010.

Rap, A., Forster, P. M., Haywood, J. M., Jones, A., and Boucher, O.: Estimating the climate impact of linear contrails using the UK Met Office climate model, Geophys. Res. Lett., 37, L20703, doi:10.1029/2010GL045161, 2010a.

Rap, A., Forster, P. M., Jones, A., Boucher, O., Haywood, J. M., Bellouin, N., and De Leon, R. R.: Parameterization of contrails in the UK Met Office Climate Model, J. Geophys. Res., 115, D10205, doi:10.1029/2009JD012443, 2010 b.

Rosenberg, P. D., Dean, A. R., Williams, P. I., Dorsey, J. R., Minikin, A., Pickering, M. A., and Petzold, A.: Particle sizing calibration with refractive index correction for light scattering optical particle counters and impacts upon PCASP and CDP data collected during the Fennec campaign, Atmos. Meas. Tech., 5, 1147-1163, doi:10.5194/amt-5-1147-2012, 2012.

Schröder, F., Kärcher, B., Duroure, C., Ström, J., Petzold, A., Gayet, J.-F., Strauss, B., Wendling, P., and Borrmann, S.: On the transition of contrails in cirrus clouds, J. Atmos. Sci., 57, 464-480, 2000.

Sonntag, D.: Advancements in the field of hygrometry, Meteorol. Z., 3, 51-66, 1994.

Stordal, F., Myhre, G., Stordal, E. J. G., Rossow, W. B., Lee, D. S., Arlander, D. W., and Svendby, T.: Is there a trend in cirrus cloud cover due to aircraft traffic?, Atmos. Chem. Phys., 5, 2155-2162, doi:10.5194/acp-5-2155-2005, 2005.

Tompkins, A. M., Gierens, K., and Rädel, G.: Ice supersaturation in the ECMWF integrated forecast system, Q. J. Meteorol. Soc., 133, 53-63, 2007.

Voigt, C., Schumann, U., Jessberger, P., Jurkat, T., Petzold, A., Gayet, J.-F., Krämer, M., Thornberry, T., and Fahey, D. W.: Extinction and optical depth of contrails, Geophys. Res. Lett., 38, L11806, doi:10.1029/2011GL047189, 2011. 
Yang, P., Hong, G., Dessler, A. E., Ou, S. S. C., Liou, K.N., Minnis, P., and Harsvardhan: Contrails and induced cirrus: Optics and radiation, B. Am. Meteor. Soc., 91, 473-478, doi:10.1175/2009BAMS2837.1, 2010.
Zerefos, C. S., Eleftheratos, K., Balis, D. S., Zanis, P., Tselioudis, G., and Meleti, C.: Evidence of impact of aviation on cirrus cloud formation, Atmos. Chem. Phys., 3, 1633-1644, doi:10.5194/acp3-1633-2003, 2003. 